OPEN ACCESS

Edited by:

Mark P. Burns,

Georgetown University, United States

Reviewed by:

Fu-Ming Zhou,

University of Tennessee Health Science Center, United States

Jiajie Diao,

University of Cincinnati, United States

${ }^{*}$ Correspondence:

Frank Hirth

frank.hirth@kcl.ac.uk

Specialty section:

This article was submitted to

Neurodegeneration,

a section of the journal

Frontiers in Neuroscience

Received: 05 December 2017

Accepted: 01 February 2018

Published: 19 February 2018

Citation:

Bridi JC and Hirth F (2018)

Mechanisms of $\alpha$-Synuclein Induced Synaptopathy in Parkinson's Disease.

Front. Neurosci. 12:80

doi: 10.3389/fnins.2018.00080

\section{Mechanisms of $\alpha$-Synuclein Induced Synaptopathy in Parkinson's Disease}

\author{
Jessika C. Bridi and Frank Hirth*
}

King's College London, Department of Basic and Clinical Neuroscience, Maurice Wohl Clinical Neuroscience Institute, Institute of Psychiatry, Psychology and Neuroscience, London, United Kingdom

Parkinson's disease (PD) is characterized by intracellular inclusions of aggregated and misfolded $\alpha$-Synuclein ( $\alpha$-Syn), and the loss of dopaminergic (DA) neurons in the brain. The resulting motor abnormalities mark the progression of PD, while non-motor symptoms can already be identified during early, prodromal stages of disease. Recent studies provide evidence that during this early prodromal phase, synaptic and axonal abnormalities occur before the degenerative loss of neuronal cell bodies. These early phenotypes can be attributed to synaptic accumulation of toxic $\alpha$-Syn. Under physiological conditions, $\alpha$-Syn functions in its native conformation as a soluble monomer. However, PD patient brains are characterized by intracellular inclusions of insoluble fibrils. Yet, oligomers and protofibrils of $\alpha$-Syn have been identified to be the most toxic species, with their accumulation at presynaptic terminals affecting several steps of neurotransmitter release. First, high levels of $\alpha$-Syn alter the size of synaptic vesicle pools and impair their trafficking. Second, $\alpha$-Syn overexpression can either misregulate or redistribute proteins of the presynaptic SNARE complex. This leads to deficient tethering, docking, priming and fusion of synaptic vesicles at the active zone (AZ). Third, $\alpha$-Syn inclusions are found within the presynaptic AZ, accompanied by a decrease in AZ protein levels. Furthermore, $\alpha$-Syn overexpression reduces the endocytic retrieval of synaptic vesicle membranes during vesicle recycling. These presynaptic alterations mediated by accumulation of $\alpha$-Syn, together impair neurotransmitter exocytosis and neuronal communication. Although $\alpha$-Syn is expressed throughout the brain and enriched at presynaptic terminals, DA neurons are the most vulnerable in PD, likely because $\alpha$-Syn directly regulates dopamine levels. Indeed, evidence suggests that $\alpha$-Syn is a negative modulator of dopamine by inhibiting enzymes responsible for its synthesis. In addition, $\alpha$-Syn is able to interact with and reduce the activity of VMAT2 and DAT. The resulting dysregulation of dopamine levels directly contributes to the formation of toxic $\alpha$-Syn oligomers. Together these data suggest a vicious cycle of accumulating $\alpha$-Syn and deregulated dopamine that triggers synaptic dysfunction and impaired neuronal communication, ultimately causing synaptopathy and progressive neurodegeneration in Parkinson's disease.

Keywords: Parkinson's disease, synapse, SNARE complex, active zone, dopamine, $\alpha$-synuclein, synaptopathy, neurodegeneration 


\section{INTRODUCTION}

Parkinson's disease (PD) is the second most common neurodegenerative disorder after Alzheimer's disease (AD) (Kalia and Lang, 2015). The pathological hallmarks of PD are intracellular proteinaceous inclusions called Lewy bodies (LB) and Lewy neurites (LN) that are predominantly formed of misfolded and aggregated forms of the presynaptic protein $\alpha$-Synuclein ( $\alpha$-Syn), and the loss of dopaminergic (DA) neurons in the substantia nigra (SN) (Spillantini et al., 1997; Lang and Lozano, 1998a,b). Loss of DA neurons in the SN leads to marked decrease of dopamine levels in synaptic terminals of the dorsal striatum (Figures 1A,B), ultimately leading to a loss of the nigrostriatal pathway (Cheng et al., 2010). The reduction of striatal dopamine triggers a range of motor symptoms including bradykinesia, uncontrollable tremor at rest, postural impairment, and rigidity which together characterize PD as a movement disorder.

The onset of $\mathrm{PD}$, however, is considered to commence at least 20 years prior to detectable motor abnormalities, when a variety of non-motor symptoms can be observed (Hawkes et al., 2010; Kalia and Lang, 2015; Mahlknecht et al., 2015). This period is referred to as the prodromal phase where patients experience a range of non-motor symptoms including constipation, olfactory dysfunction (hyposmia), sleep disturbance, obesity and depression (Figure 1C; Hawkes et al., 2010; Kalia and Lang, 2015; Mahlknecht et al., 2015). During the prodromal phase of PD and PD-related disorders, which precedes degenerative cell loss, the expression levels of a range of proteins involved in synaptic transmission are altered in the prefrontal and cingulate cortex, and SN (Dijkstra et al., 2015; Bereczki et al., 2016; Table 1), suggesting that both nonmotor and motor symptoms are caused by impaired synaptic communication. This data indicates that neurodegeneration in $\mathrm{PD}$ is a dying back-like phenomenon which starts at synaptic terminals in the striatum and progresses along the nigrostriatal pathway, ultimately affecting homeostasis and survival of DA cell bodies in the SN (Hornykiewicz, 1998; Calo et al., 2016; Caminiti et al., 2017). It is due to these early-onset synaptic alterations observed prior to DA neuron loss, PD has also been classified as a synaptopathy (Brose et al., 2010; Schirinzi et al., 2016).

The majority of PD cases are sporadic with unknown cause. However, familial cases with autosomal dominant or recessive Mendelian inheritance have revealed fundamental insights into pathogenic mechanisms underlying PD (Keane et al., 2011; Massano and Bhatia, 2012; Kalia and Lang, 2015). The most commonly identified genetic mutations linked to heritable PD were found in the genes $S N C A$ and $L R R K 2$, responsible for

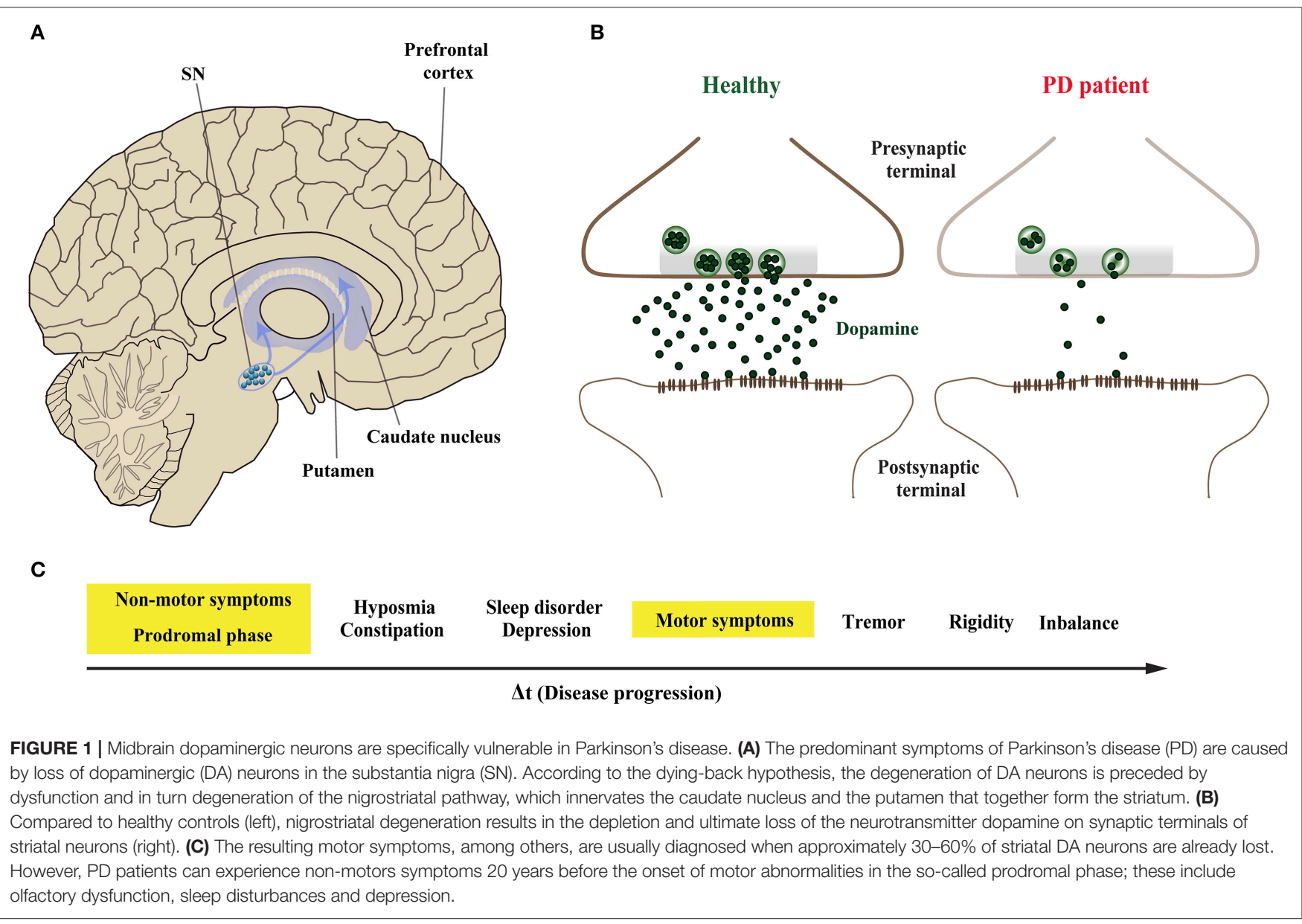


TABLE 1 | Alterations of presynaptic proteins seen with $\alpha$-Syn related proteinopathy in PD and DLB patients and rodent animal models.

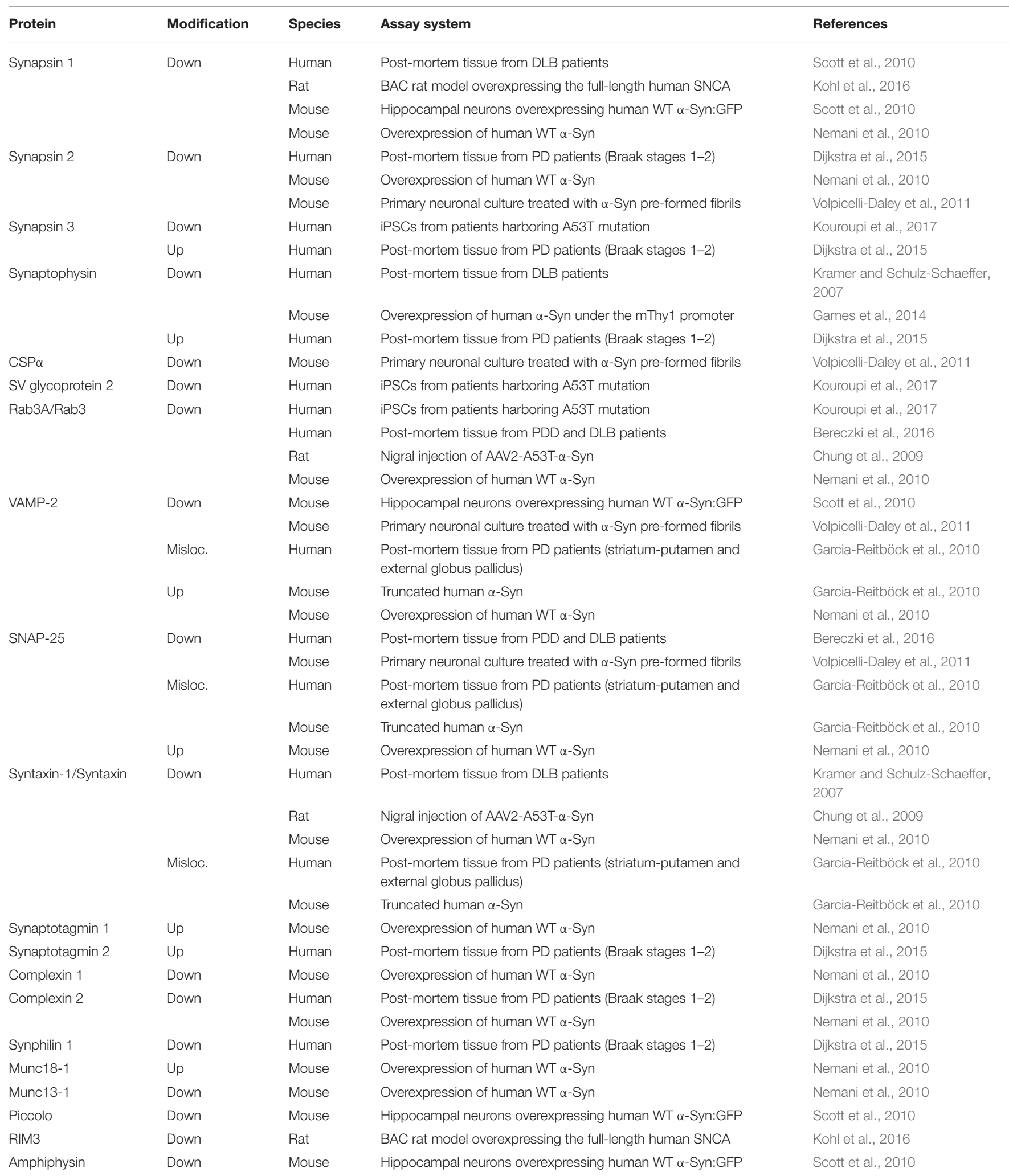


an autosomal-dominant forms of PD, and in Parkin, PINK1, $D J-1$, and ATP13A2 which account for PD with autosomal recessive mode of inheritance (Klein and Westenberger, 2012; Ferreira and Massano, 2017). PD-related mutations in PINK1 and Parkin and the functional interaction of the two proteins led to the identification of mitochondrial dysfunction as one of the major pathogenic pathways underlying PD (reviewed in Exner et al., 2012; Pickrell and Youle, 2015). Additionally, PD-related mutations in Glucocerebrosidase (GBA), SCARB2 and ATP13A2 established lysosomal storage dysfunction as a second pathogenic pathway that also contributes to PD etiology (reviewed in Hardy, 2010; Gan-Or et al., 2015).

However, among the identified PD-related genes, SNCA encoding the presynaptic protein $\alpha$-Syn remains the most potent culprit underlying PD. Accumulated $\alpha$-Syn is the main component of $\mathrm{LB}$, and together with genome-wide association studies it has been shown to have central pathogenic role in both familial and sporadic PD (Satake et al., 2009; SimónSánchez et al., 2009). Yet despite recent progress, the pathogenic mechanisms underlying $\alpha$-Syn related PD are only starting to emerge. Here we provide a focussed review emphasizing current knowledge on synaptic function and the various mechanisms of $\alpha$-Syn induced synaptopathy, and its role in the early stages of PD progression.

\section{ACCUMULATION OF $\alpha$-SYNUCLEIN: THE PATHOLOGICAL HALLMARK OF PD}

$\alpha$-Syn is a small soluble cytoplasmic protein of 140 amino acid; its main protein domains comprise an amphipathic region, non-amyloid- $\beta$ component (NAC) domain and an acidic tail (Figure 2A; Maries et al., 2003; Venda et al., 2010). $\alpha$-Syn together with $\beta$-Syn and $\gamma$-Syn belong to the synuclein protein family (Goedert, 2001; Marques and Outeiro, 2012). The three Synuclein proteins are 55-62\% identical in sequence and have similar domain organization (Goedert, 2001); all three are highly expressed in the human brain (Goedert, 2001). Additionally, $\alpha$-Syn and $\beta$-Syn share the same subcellular distribution at presynaptic terminals in neurons (Jakes et al., 1994; Goedert, 2001). However, $\alpha$-Syn is the only protein of the synuclein family to be found in LB and to be implicated in PD pathogenesis (Goedert et al., 2017).

Several dominant-inherited single point mutations in SNCA gene have been identified in families that develop early onset PD (Polymeropoulos, 1997; Krüger et al., 1998; Zarranz et al., 2004; Appel-Cresswell et al., 2013; Lesage et al., 2013; Pasanen et al., 2014). Subsequent studies identified multiplications of the SNCA gene locus (Singleton, 2003; Farrer et al., 2004) and SNCA polymorphisms which are associated with high risk of developing the disease (Satake et al., 2009; Simón-Sánchez et al., 2009). In line with dosage-related $\alpha$-Syn pathology, higher doses of $\alpha$ Syn observed in patients with duplication and triplication of the SNCA gene locus directly correlate with cognitive decline, motor and non-motor symptoms and severity of neurodegenerative phenotypes (Venda et al., 2010). This data is strong evidence that dysfunction and accumulation of $\alpha$-Syn plays a key role in both familial and sporadic forms of PD. In addition to LB inclusions, $\alpha$-Syn has been shown to accumulate in axons (Braak et al., 1999) and in the presynaptic terminal (Kramer and SchulzSchaeffer, 2007), suggesting these pathogenic accumulations are a key trigger of onset and formation of PD-related synaptopathy (Stefanis, 2012; Schirinzi et al., 2016) (Box 1).

In the healthy brain and central nervous system (CNS), wild type $\alpha$-Syn is available in its native conformation as soluble monomers. These are thought to mediate its physiological

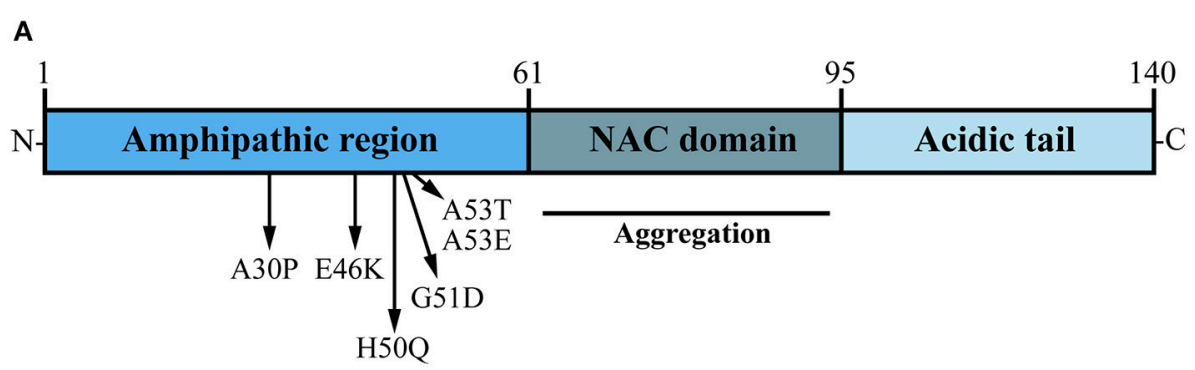

B

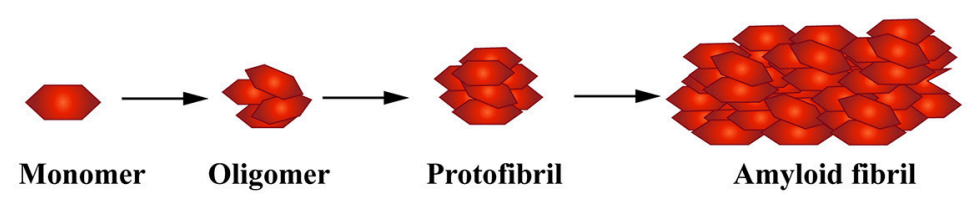

FIGURE 2 | The presynaptic protein $\alpha$-Synuclein is a pathological seed for Parkinson's disease formation. (A) $\alpha$-Synuclein $(\alpha$-Syn) is a small soluble cytoplasmic protein of 140 amino acid encoded by the SNCA gene; its main protein domains comprise an N-terminal amphipathic region, a non-amyloid- $\beta$ component (NAC) domain and a C-terminal acidic tail. Several dominant inherited missense mutations have been identified in the amphipathic region causing early-onset PD, whereas the NAC domain has been implicated in $\alpha$-Syn aggregation. (B) Under normal physiological conditions, $\alpha$-Syn monomers function in a dynamic equilibrium between a soluble and a membrane-bound state. Under cellular stress and in disease-relation conditions, $\alpha$-Syn monomers can interact leading to oligomers that buffer the formation of protofibrils, ultimately causing the formation of amyloid- $\beta$ sheet fibrils that aggregate into Lewy bodies (LB). 


\section{BOX $1 \mid \alpha$-Syn-mediated synaptopathy - open questions and future directions.}

Progress over the past two decades revealed compelling evidence that one of the major sites of $\alpha$-Syn-mediated toxicity are presynaptic terminals. Once initiated, the resulting neuronal dysfunction can lead to both cell intrinsic and cell-extrinsic toxicity. Cell-intrinsic mechanisms cause axonal degeneration which progresses toward the cell body, eventually leading to dying-back like neurodegeneration. Cell-extrinsic mechanisms cause transmission of $\alpha$-Syn oligomers along synaptic connections and the ultimate progression of synucleopathy throughout the patient brain. Neither of these mechanisms are fully understood, nor how $\alpha$-Syn oligomerizes in the first place, thus precluding the development of efficient therapeutic treatments. To progress toward therapy, several open questions need to be addressed.

\section{Conformational changes of $\alpha-S y n$}

$\alpha$-Syn accumulates in synapses and axons and forms neuronal inclusions. What triggers $\alpha$-Syn self-assembly and in turn the formation of toxic species of misfolded $\alpha$-Syn? How do different types of oligomers serve as template for fibril formation of $\alpha$-Syn? There is evidence that the formation of fibrils, rather than toxic species themselves, mediates $\alpha$-Syn toxicity (Lashuel et al., 2013). Which aspect of this process is so pathogenic to neurons? It also remains to be shown whether $\alpha$-Syn may form various types of oligomeric states with different toxicity. To address these questions in a systematic way, first and foremost reliable markers are required to monitor, both in vitro and in vivo, the different and progressive conformational changes of $\alpha$-Syn and their impact on toxicity.

$\alpha$-Syn acts as a chaperone for the presynaptic SNARE complex. It controls assembly, maintenance and distribution of this highly reactive complex of proteins. Can this environment be responsible for triggering the pathologic cascade to form $\alpha$-Syn oligomers and fibrils? The increased stability and longer half-life of mutant forms of $\alpha$-Syn, such as A30P and A53T, increase their potential of aggregation (Bennett et al., 1999; Cuervo et al., 2004). In addition, failure of proteasomal degradation and autophagy in PD have been linked to high levels of $\alpha$-Syn. Together, these factors can favor the accumulation of pathologic $\alpha$-Syn. Small molecule and compound screens together with in vivo genetic screens in animal models are necessary to identify mechanisms and molecules that can abrogate, hamper or at least delay misfolding of $\alpha$-Syn, and thus progression of disease.

\section{Accumulation of $\alpha$-Syn and synaptic defects}

What is the threshold concentration of toxic $\alpha$-Syn species, such as oligomers and fibrils, to trigger biochemical and cellular alteration that lead to neuronal dysfunction? Oligomeric forms of $\alpha$-Syn are considered the most toxic species at the synapses (Ingelsson, 2016) and their structure appears different between mutant forms and wild type $\alpha$-Syn (Tosatto et al., 2015). This suggests the severity of pathology may not only relate to the abundance and formation of oligomers but also to their structural and functional properties. It remains to be shown whether distinct oligomeric $\alpha$-Syn species, and their way of formation, exert differential toxic mechanisms that specifically impair the presynaptic terminal and neurotransmission.

Do oligomeric and fibrils of $\alpha$-Syn cause a dominant negative effect in synaptic function? Can $\alpha$-Syn oligomers, for instance, reduce the activity of its synaptic partners and neuronal signaling pathways? The effect of different lengths and concentrations of $\alpha$-Syn oligomers on SNARE-mediated membrane fusion and docking are one way to measure toxicity, as previously shown in vitro (Choi et al., 2013; Lai et al., 2014). In vitro protein-reconstituted systems are necessary to test the effects of different toxic $\alpha$-Syn species on fast $\mathrm{Ca}^{2+}$-triggered neurotransmitter release and their in vivo toxicity in synaptic transmission.

\section{$\alpha$-Syn transmission and transcellular progression of disease}

Several studies using animal models have given strength to Braak's hypothesis for $\alpha$-Syn propagation within interconnected brain regions (reviewed in Oueslati et al., 2014). However, the mechanisms underlying $\alpha$-Syn transmission remain poorly understood. Which $\alpha$-Syn toxic species are "seeding" for trans-synaptic transmission? What is the minimum concentration of toxic $\alpha$-Syn required to trigger transmission? Can extracellular $\alpha$-Syn and exosomes be efficiently cleared by pharmacological or gene therapy approaches without affecting the intracellular endogenous $\alpha$-Syn? To address these questions, in vivo systems to allow monitoring of $\alpha$-Syn transmission are required. For example, Drosophila melanogaster has been successfully used to study transcellular spreading of human huntingtin (Htt) (Babcock and Ganetzky, 2015). This model system has opened avenues for unbiased whole genome screening of cellular mechanisms and pharmacological interventions of $\mathrm{Htt}$ transmission. $\alpha$-Syn transmissibility could also be studied in brain organoids derived from induced pluripotent stem cells (iPSCs) of healthy individuals and patients harboring $\alpha$-Syn mutations. Although an in vitro culture, organoids resemble the in vivo architecture, functionality, and genetic signature of original tissues (Dutta et al., 2017). Moreover, organoids develop neuronal networks that can be modulated by sensory stimulation (Quadrato et al., 2017). Hence organoids can be used to study $\alpha$-Syn propagation along interconnected neuronal networks.

function in presynaptic terminals (Burré, 2015). Although LB are characterized by $\beta$-sheet aggregated fibrils of $\alpha$-Syn (Spillantini et al., 1997; Rodriguez et al., 2015), in vitro studies have shown that the formation of oligomers, not fibrills, are a distinct hallmark of $\alpha$-Syn mutations such as A30P and A53T, which are known to cause early-onset familial PD (Conway et al., 2000). The NAC domain of $\alpha$-Syn is a hydrophobic sequence formed of 12 amino acids which forms the core part of the $\alpha$-Syn protein and is key for its transformation from soluble monomer to oligomers, into protofibrils and finally aggregating fibrils (Figure 2B; Giasson et al., 2001). In vitro studies performed by Narhi and colleagues demonstrated that wild type, as well as mutant $\mathrm{A} 30 \mathrm{P}$ and $\mathrm{A} 53 \mathrm{~T} \alpha$-Syn can form insoluble $\beta$ sheet structured fibrillar aggregates at physiological temperature (Narhi et al., 1999). Importantly, mutant forms of $\alpha$-Syn promote fibril formation more rapidly than the wild type $\alpha$-Syn protein.
The carriers of A30P and A53T $\alpha$-Syn point mutations are also more prone to $\alpha$-Syn aggregation and toxicity, hence correlating with increased vulnerability and earlier onset of PD formation in SCNA mutant carriers (Li et al., 2001; Ingelsson, 2016).

Aggregated and oligomeric $\alpha$-Syn are also implicated in prionlike transmission of progressive PD pathology along distant but connected brain regions (Spillantini et al., 1997; Jucker and Walker, 2013). The accumulation of $\alpha$-Syn in LB undergo an ascending pattern of distribution, from the lower brainstem and olfactory bulb into the limbic system and ultimately to the neocortex (Braak et al., 2003). Several hypotheses attempt to address the cellular mechanisms underlying progressive $\alpha$ Syn transmission spreading throughout these brain regions (Longhena et al., 2017). Few studies have supported that cellto-cell transmissibility of $\alpha$-Syn occurs at the synapses, through physiological processes such as exocytosis and endocytosis or due 
to synaptic degeneration (Frost and Diamond, 2009; Guo and Lee, 2014). Although the underlying mechanisms so far remained elusive, there is strong evidence that progressive transmission correlates with severity of the disease (Hawkes et al., 2010) (Box 1).

\section{WHERE DOES PD PATHOLOGY START?}

Several neurodegenerative diseases exhibit early impairment of synaptic function (Bae and Kim, 2017). This often occurs concomitantly with the manifestation of cognitive symptoms, with a neuronal degeneration emerging at later stages of disease (Milnerwood and Raymond, 2010; Schulz-Schaeffer, 2010; Picconi et al., 2012). Thus, synaptic dysfunction is considered to be the first step followed by active deconstruction of axons and loss of neuronal connectivity, eventually leading to the death of neuronal perikarya (Figure 3; Scott et al., 2010; Lu et al., 2014; Morales et al., 2015; Schulz-Schaeffer, 2015; Calo et al., 2016; Grosch et al., 2016; Tagliaferro and Burke, 2016; Bae and Kim, 2017; Fang et al., 2017; Kouroupi et al., 2017; Roy, 2017). This succession of events suggests that neural death in PD is initiated at synaptic terminals and progresses proximally toward neural cell bodies in a dying back-like manner.

In line with this hypothesis, almost 20 years ago Hornykiewicz suggested that formation of PD starts by affecting axons in the dorsal striatum prior to degeneration of DA neurons in the SN (Hornykiewicz, 1998). However, this hypothesis only recently gained strong support by a range of pathological and

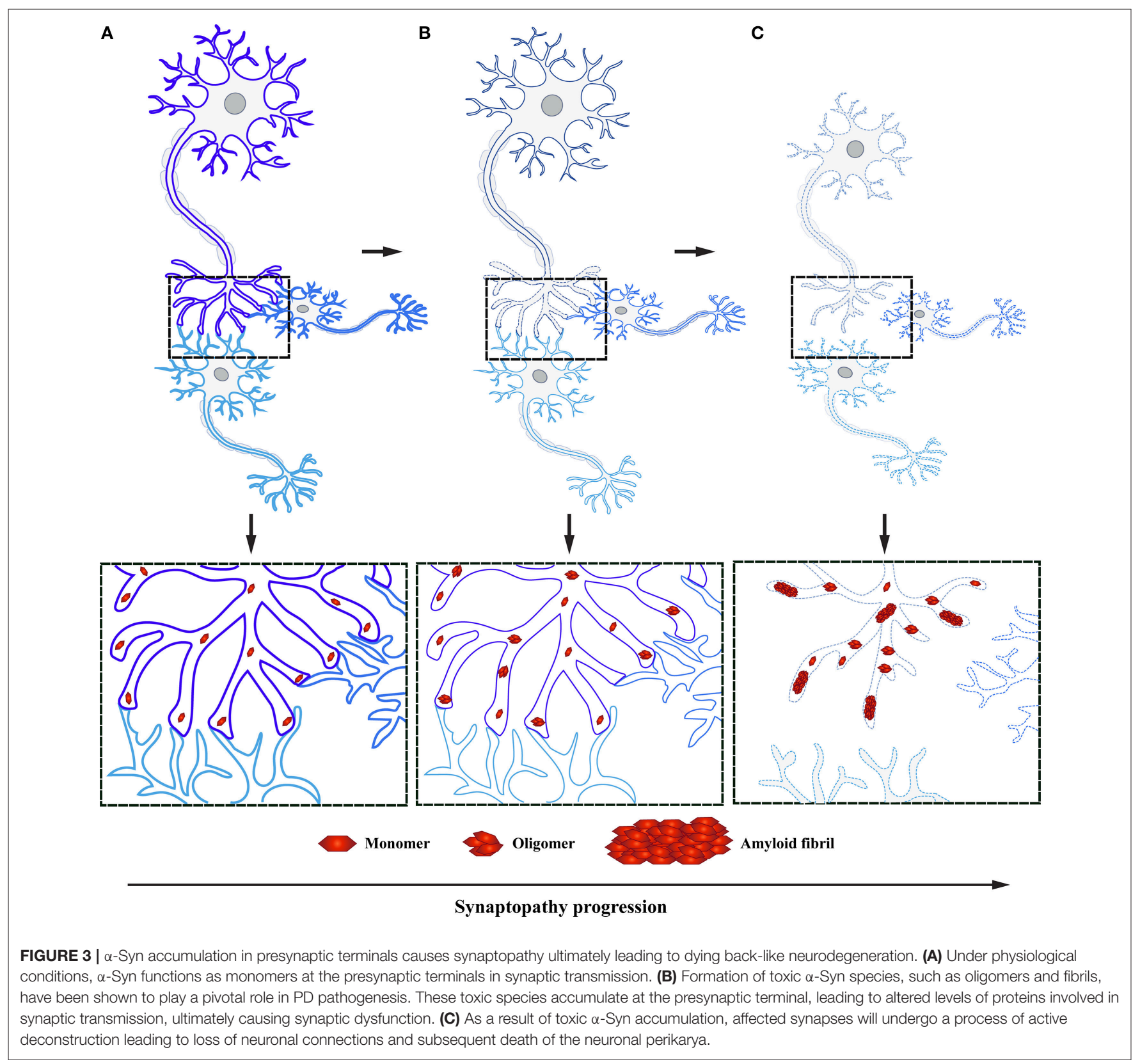


molecular data. The first evidence that axons were affected in PD came from the pioneer study performed by Braak et al. (1999). They were able to demonstrate that extensive and very thin $\alpha$-Syn inclusions were not only present in LB inclusions at the neuron soma but also present in axonal processes (Braak et al., 1999). More recent studies found $\alpha$-Syn localized within axonal dystrophic neurites in the striatum of patients with Alzheimer's disease (AD) and PD (Duda et al., 2002), as well as in multiple system atrophy (MSA) and dementia with Lewy body (DLB) (Galvin et al., 1999). The localization of $\alpha$-Syn was further studied through the development of a technique called paraffin-embedded tissue (Kramer and SchulzSchaeffer, 2007). This method allowed for the detection of abundant $\alpha$-Syn micro-aggregates in the neuropil rather than in the cell body of DLB patient brains. Furthermore, Kramer and Schulz-Schaeffer showed the abundance of synaptic $\alpha$ Syn micro-aggregates exceeded the amount of $\alpha$-Syn aggregates in $\mathrm{LB}$ or LN by one to two orders of magnitude. Their filtration technique revealed $50-92 \%$ of $\alpha$-Syn micro-aggregates were found entrapped within the presynaptic terminal. This result correlated with the striking downregulation of presynaptic proteins like syntaxin and synaptophysin, and postsynaptic proteins such as PSD95 and drebrin (Kramer and SchulzSchaeffer, 2007).

This new mechanistic insight exploring synaptic deficits as a starting point in $\alpha$-Syn related pathology is in agreement with previous findings, where $\alpha$-Syn aggregates were observed in axon terminals preceding the formation of LB in DLB and correlating with cognitive impairment (Marui et al., 2002). Moreover, similar to DLB, PD patient data demonstrates that these individuals experience first locomotor symptoms once $50-60 \%$ of DA striatal terminals have already been lost, while the loss of DA neurons in the SN is believed to be only around 30\% (reviewed in Burke and O'Malley, 2013). These observations have been independently confirmed by positron emission tomography; PD patients in early stages of the disease show extensive axonal damage and loss of nigrostriatal pathway connectivity (Caminiti et al., 2017). This data suggests that $\alpha$-Syn pathology is abundant in presynaptic terminals and axons, in line with the observation that its normal localization is predominantly in presynaptic terminals (Figure 3). Yet little is known how early accumulation of toxic $\alpha$-Syn species impairs synaptic homeostasis and function, ultimately leading to DA neurodegeneration in PD.

\section{THE JANUS FACE OF PRESYNAPTIC $\alpha$-SYN: PHYSIOLOGY AND PATHOLOGY}

Synapses are the intercellular junctions between a presynaptic neuron and a postsynaptic cell (Südhof, 2012). They are used to transmit signal between neurons in the CNS via exocytosis of neurotransmitter allowing an organized flux of information through the brain (Lepeta et al., 2016). Synapses are composed of a presynaptic terminal, synaptic cleft and postsynaptic terminal which require a complex and tight regulation for proper neurotransmission to occur (Figure 4; Südhof and Rizo, 2011; Südhof, 2012).
The presynaptic nerve terminal is a specialized secretory machinery that releases neurotransmitters by synaptic vesicle (SV) exocytosis in response to an action potential. It is at the presynaptic terminal where $\alpha$-Syn is hypothesized to play its physiological or pathological role (Katz, 1969; Chandra et al., 2005; Burré, 2015). By receiving an action potential, calcium $\left(\mathrm{Ca}^{2+}\right)$ channels open, thereby allowing influx of $\mathrm{Ca}^{2+}$ into the presynaptic terminal (Südhof, 2013b). This $\mathrm{Ca}^{2+}$ influx promotes the assembly of a molecular machinery composed mainly of the $\mathrm{Ca}^{2+}$ sensor synaptotagmin and the soluble NSF-attachment protein receptor (SNARE) complex, including VAMP-2, SNAP-25, and Syntaxin-1 (Südhof, 2013a). Ultimately, this molecular machinery will trigger SV trafficking from the closest pool, the readily releasable pool (RRP), to be tethered, docked and fused to the presynaptic plasma membrane at a defined region of the presynaptic terminal called the active zone (AZ) (Figure 4), for subsequent release of neurotransmitter in the synaptic cleft (Südhof, 2000, 2012, 2013b; Alabi and Tsien, 2012). In addition to the SNARE complex, a subfamily of highly conserved small GTPases called Rab are implicated in intracellular trafficking of vesicles and the recruitment of SV in the AZ (Binotti et al., 2016).

The AZ matrix is composed of several proteins including RIM, ELKS (also known as ERC/CAST/Rab6IP2), Munc13, Bassoon/Piccolo, Rim-BP, and Liprin- $\alpha$ (Schoch and Gundelfinger, 2006; Südhof, 2012; Wang et al., 2016). The $\mathrm{AZ}$ is a highly organized structure restricted to the plasma membrane region, opposite to the postsynaptic density marked by postsynaptic density protein 95 (PSD95). Functionally, AZ proteins dock SVs to be fused with the plasma membrane and release their neurotransmitter content into the synaptic cleft (Figure 4; Wang et al., 2016). After exocytosis, the SV membrane is retrieved from the synaptic cleft by endocytosis, either via clathrin-dependent slow or clathrin-independent fast modes of endocytosis (Saheki and De Camilli, 2012). The SV are locally loaded with neurotransmitter, hence being recycled to allow another round of exo-endocytotic membrane cycling (Südhof, 2004; Gross and von Gersdorff, 2016). This mechanism allows the neurons to sustain a high firing rate without depletion of the SV pools (Saheki and De Camilli, 2012; Gross and von Gersdorff, 2016).

Deficiencies in synaptic transmission have been observed in response to both knock down or overexpression of $\alpha$-Syn, suggesting that it has a role in the regulation of neurotransmitter release, synaptic function and homeostasis (Box 1) (Kahle et al., 2000; Lee et al., 2008; Zhang et al., 2008; Lashuel et al., 2013; Vargas et al., 2017). Under physiological conditions, $\alpha-$ Syn is found at the presynaptic terminal (Maroteaux et al., 1988) and exists in a dynamic equilibrium between a soluble and a membrane-bound state (Burré, 2015). Specifically, $\alpha$-Syn is localized to presynaptic boutons due to its preference for membranes with high curvature (Middleton and Rhoades, 2010; Jensen et al., 2011). Despite its known presynaptic localization, the physiological functions of $\alpha$-Syn remain poorly understood. In the following sections, we will discuss the evidence for physiological and pathological roles of $\alpha$-Syn in the presynaptic terminal. 


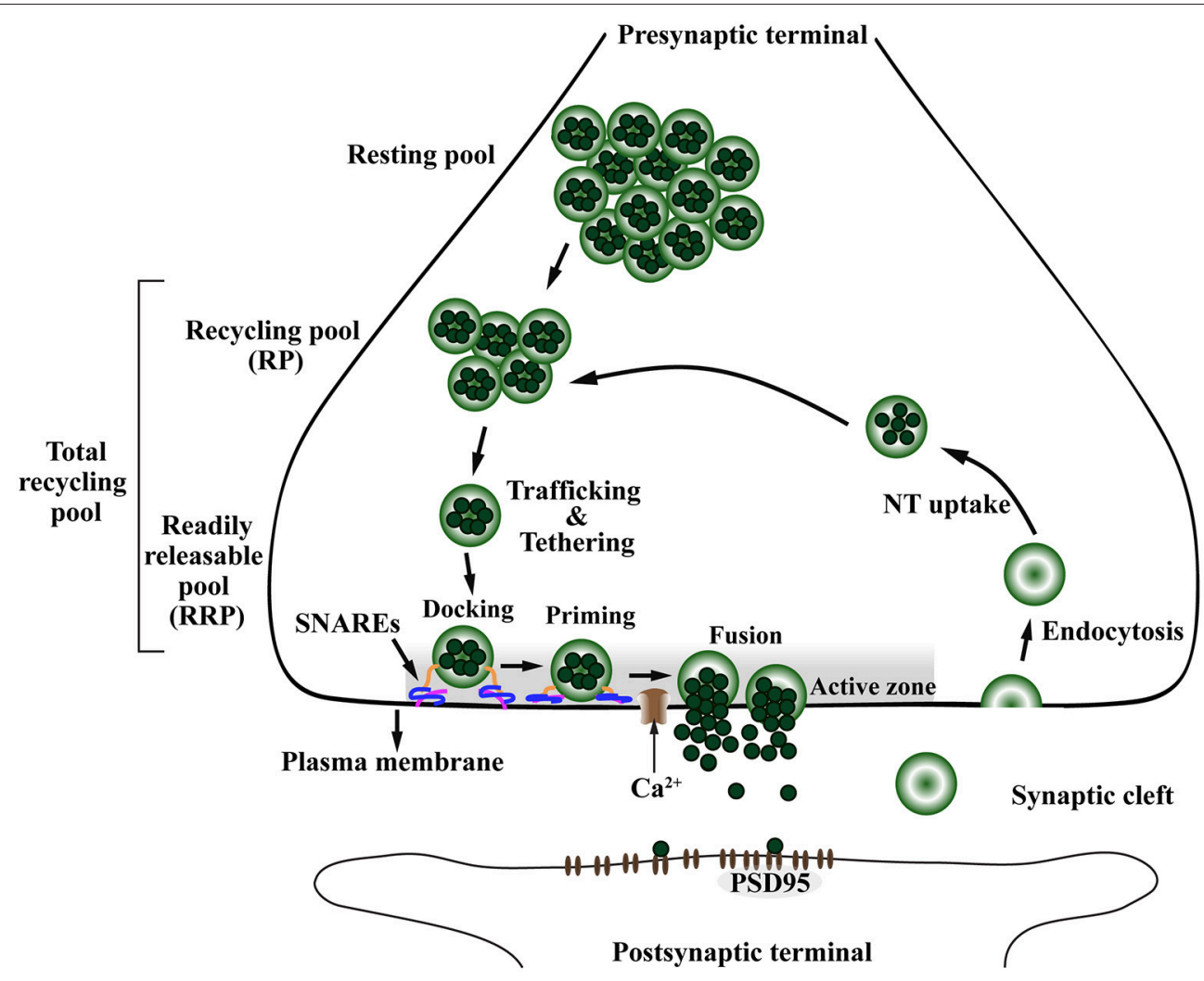

FIGURE 4 | The presynaptic exo-endocytotic cycle regulating neurotransmitter release is specifically affected in $\alpha$-Syn-related synaptopathies. Upon an incoming action potential, calcium $\left(\mathrm{Ca}^{2+}\right)$ channels become permeable to $\mathrm{Ca}^{2+}$ entry in the presynaptic terminal. This activates a molecular machinery including the SNARE complex proteins that recruit synaptic vesicles (SV) from the proximal resting and recycling (RP) pools via trafficking and tethering to form the readily releasable pool (RRP). After docking and priming, RRP vesicles undergo SNARE-mediated membrane fusion at the active zone (AZ, shaded area), ultimately leading to neurotransmitter (NT) release into the synaptic cleft. After exocytosis, the SV membrane is retrieved to the presynaptic terminal via endocytosis, to be filled with NT (NT uptake) and re-enter the exo-endocytotic cycle, thereby granting the neuron its ability to sustain high firing rates. PSD95, postsynaptic density protein-95.

\section{$\alpha$-Syn Affects Synaptic Vesicle Pools and Their Trafficking in the Presynaptic Terminal}

The SV pools can be divided accordingly to the number of SVs and distance from the AZ (Südhof, 2000; Alabi and Tsien, 2012). The RRP is the closest in proximity to the AZ, containing the smallest number of vesicles and holding the highest fusion probability. The recycling pool (RP) is located above the RRP and has three times more vesicles than the RRP. The RP repopulates vacancies at the $\mathrm{RRP}$ which are often rate-limiting during persistent activity and along with the RRP compose the total recycling pool (Alabi and Tsien, 2012). Finally, the most distal SV pool is called the resting pool, this is the largest pool of SVs that remain unreleased even after prolonged synaptic stimulation (Figure 4; Südhof, 2000; Alabi and Tsien, 2012).

$\alpha$-Syn has been shown to be associated with the recycling pool of SVs and its proteins. Depletion of $\alpha$-Syn, through the use of antisense oligonucleotides, induces a decrease in the availability of reserve synaptic vesicle pool in primary cultured hippocampal neurons (Murphy et al., 2000). $\alpha$-Syn knockout (KO) mice revealed a striking deficiency of undocked vesicles without affecting docked vesicles at the RRP (Cabin et al., 2002). In addition, the refilling of the docked vesicles by the resting pool after depletion was slower in the synapses of mice lacking $\alpha$-Syn (Cabin et al., 2002). Together this data strongly supports a role of $\alpha$-Syn in SV trafficking at the presynaptic terminal by modulating vesicular dynamics and maintaining the homeostasis of vesicle RPs.

Overexpression of wild type and mutant $\alpha$-Syn in Chromaffin and PC12 cells revealed inhibited evoked neurotransmitter release (Larsen et al., 2006). This inhibition was attributed to a smaller population of RRP, suggesting that $\alpha$-Syn inhibits the vesicle "priming" step which is the intermediate step between vesicle docking and fusion of synaptic vesicles at the AZ (Larsen et al., 2006). Furthermore, overexpression of wild type $\alpha$-Syn to similar levels observed in PD patients with duplication and triplication of the SNCA gene, inhibited neurotransmitter exocytosis by affecting the size of the RP (Nemani et al., 2010; Scott and Roy, 2012).

Interestingly, ultrastructural analysis of the synapse in mice overexpressing human wild type $\alpha$-Syn demonstrated the total number of SVs in the presynaptic terminal was not altered. 
Instead, these animals displayed reduced numbers of SVs at a close proximity to the AZ, whereas numbers of SVs at greater distances were increased (Nemani et al., 2010). Furthermore, this study concluded that exocytotic deficits caused by $\alpha$-Syn overexpression were not only caused by reduced size of the RP, but also due to disturbances of SV reclustering after endocytosis (Nemani et al., 2010). These findings demonstrate high levels of $\alpha$-Syn can trigger impairment of exocytosis via alteration of SV pools in absence of neurodegeneration.

\section{The SNARE Complex Related to $\alpha$-Syn Function and Dysfunction}

The SNARE proteins are crucial to allow SVs to fuse with the plasma membrane at the AZ to release neurotransmitter (Südhof and Rizo, 2011). The subsequent exocytosis requires the assembly of presynaptic machinery proteins thousands of times per minute. During each episode, the SNARE complex assembly and disassembly gives rise to extremely reactive unfolded SNARE protein intermediates, exposing the presynaptic terminal to potentially vulnerable activity-dependent degeneration (Burré et al., 2010; Südhof and Rizo, 2011). $\alpha$-Syn has been shown to act as a chaperone to promote SNARE complex assembly and to support its folding through direct binding to VAMP-2 and phospholipids on synaptic vesicles (Burré et al., 2010).

In line with these observations, $\alpha$-Syn overexpression is able to rescue neurodegeneration observed in $\operatorname{CSP} \alpha \mathrm{KO}$ mice by chaperoning the assembly of the SNARE complex, while concomitant knockout of $\alpha$-Syn exacerbates the $\operatorname{CSP} \alpha \mathrm{KO}$ phenotype (Chandra et al., 2005). CSP $\alpha$ acts as a chaperone of the SNARE complex by supporting the functional ability of SNAP-25 to engage in a complex with Syntaxin-1 and VAMP2 (Figure 5A; Sharma et al., 2011). The chaperone function of $\operatorname{CSP} \alpha$ within the SNARE complex is shared with $\alpha$-Syn, however the mechanisms differ. $\alpha$-Syn binds to VAMP-2 via its C-terminal (Burré et al., 2010) which appears to be essential for $\alpha$ Syn mediated neuroprotection because the A30P $\alpha$-Syn mutant, which is deficient in its ability to bind to membranes, failed to rescue $\operatorname{CSP} \alpha \mathrm{KO}$ mice (Chandra et al., 2005). This role of native $\alpha$-Syn in assisting SNARE complex assembly contributes to clustering of SV at the AZ (Figure 5A). Besides functioning as chaperone, $\alpha$-Syn is also important for maintenance and redistribution of the SNARE complex which is directly implicated in neurotransmitter release, including dopamine (Burré et al., 2010; Diao et al., 2013).

The synaptic accumulation of oligomers and aggregated $\alpha$ Syn and its interaction with components of the presynaptic machinery, such as SNARE proteins, is likely to underlie at least one of the pathological mechanisms that lead to synaptic dysfunction in the early stages of PD (Box 1) (Figure 5B). In support of this hypothesis, studies in vitro have demonstrated large $\alpha$-Syn oligomers bind to the N-terminal domain of VAMP2, thus blocking SNARE-mediated vesicle docking (Choi et al., 2013), which in vivo could be directly linked to impaired exocytosis of neurotransmitters in overexpression models of $\alpha$ Syn. Interestingly, another in vitro study by Lai and co-authors revealed that levels and different toxic species of $\alpha$-Syn inhibit synaptic vesicle docking via distinct mechanisms (Lai et al., 2014). These data suggest that $\alpha$-Syn may form various types of oligomeric states with different toxicity, as has been shown for aggregated tau protein in tauopathies (Goedert, 2015). Moreover, Scott and colleagues showed that cultured hippocampal neurons from transgenic animals overexpressing human $\alpha$-Syn displayed absence of endogenous synaptic proteins, including the SNARE complex protein VAMP-2 and SV proteins amphiphysin and synapsin-1 (Scott et al., 2010). Neurons overexpressing fluorescent human $\alpha$-Syn demonstrated marked deficits in neurotransmitter release, in addition to reduced numbers of SVs, and enlargement of the remaining SVs (Scott et al., 2010). Studies investigating levels of synaptic proteins belonging to the SNARE complex in PD, PD with dementia (PDD) and DLB post-mortem samples also reported misregulation of proteins belonging to the SNARE complex (Kramer and Schulz-Schaeffer, 2007; Dijkstra et al., 2015; Bereczki et al., 2016, 2018). Moreover, an in vitro model of $\alpha$-Syn toxicity, primary neuronal cultures exposed to preformed $\alpha$-Syn fibrils exhibited loss of the SNARE complex proteins VAMP2 and SNAP-25, as well as the SV proteins CSP $\alpha$ and synapsin-2 (Volpicelli-Daley et al., 2011). Volpicelli-Daley and colleagues further investigated the impact of accumulation of these preformed $\alpha$-Syn fibrils in neural network activity. Interestingly, they found that impaired hippocampal network activity occurred much earlier than the detected reduction in synaptic protein levels, suggesting that $\alpha$-Syn pathology can have a major impact on the coordination of neuronal communication and connectivity (Box 1) (Volpicelli-Daley et al., 2011).

Conversely, a mouse model expressing human truncated $\alpha$ Syn leading to $\alpha$-Syn aggregates did not show changes in levels of synaptic proteins but rather caused age-dependent redistribution and accumulation of SNAP-25, Syntaxin-1, and VAMP-2 in the striatum accompanied by an age-dependent reduction in dopamine release (Garcia-Reitböck et al., 2010). SNARE proteins were also redistributed in the striatum and external globus pallidus of early-onset PD patients (Garcia-Reitböck et al., 2010). Taken together, evidence from transgenic mouse models and PD patients demonstrate that accumulated $\alpha$-Syn alters the levels and/or localization of SNARE proteins at the presynaptic nerve terminal. These findings suggest that $\alpha$-Syn accumulation causes a toxic gain of function phenotype at the synapses, thus impairing their function and connectivity.

\section{Accumulated $\alpha$-Syn Impairs Rabs and Their Function in Synaptic Vesicle Trafficking}

The trafficking of synaptic vesicles within the presynaptic terminal is vital to recruit them from the SV pools into the active zone (Figure 4; Südhof, 2000). This is a complex process that involves a significant number of proteins and must be tightly controlled (Takamori et al., 2006; Südhof, 2013b). Amongst the proteins involved in presynaptic vesicle trafficking, a superfamily of highly conserved small GTPases called Rab act as the master regulator of intracellular trafficking processes, including vesicle budding and uncoating, motility, tethering and fusion (reviewed in Kelly et al., 2012). Rab3A protein, for instance, is abundant in SV with its activity regulated by two effectors: Rabphilin and RIM 


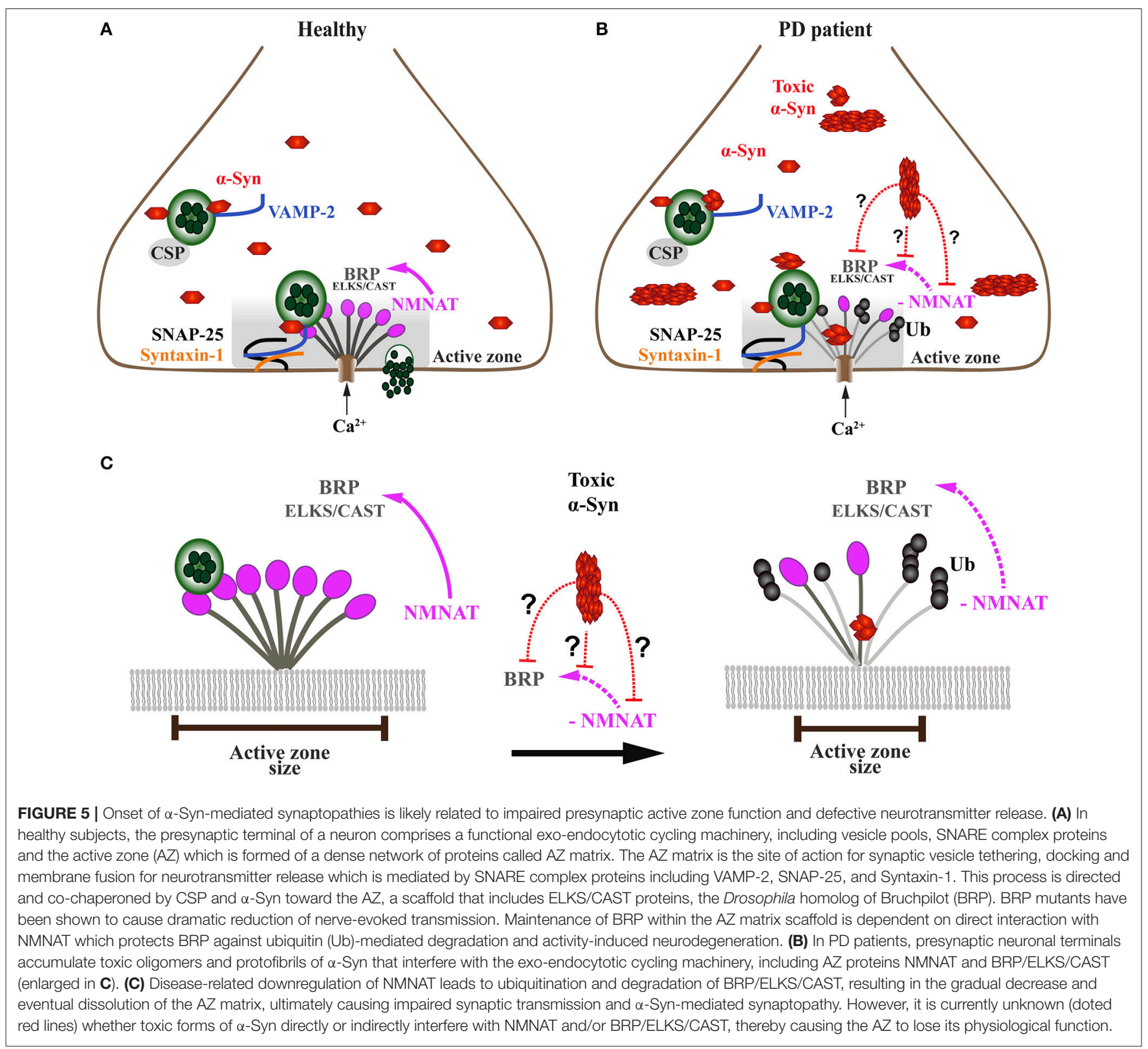

(for Rab3 interacting molecules; Shirataki et al., 1993; Wang et al., 1997). Mechanistically, Rab3A is part of a complex formed by the AZ proteins Munc13 and RIM, designed to capture SVs for final membrane attachment called tethering and to prepare them for synaptic release (Wang et al., 1997; Dulubova et al., 2005).

$\alpha$-Syn was shown to interact and cause defects in vesicular trafficking pathways including those taking place at the presynaptic terminal of neurons (Dalfó et al., 2004; Gitler et al., 2008; Abeliovich and Gitler, 2016). In line with this observation, several members of Rab GTPase family have been identified to interplay with $\alpha$-Syn (Chutna et al., 2014; Gonçalves et al., 2016). This interaction has also been observed in post-mortem tissue of DLB and MSA patients with LB pathology where $\alpha$-Syn abnormally interacts with Rab3A. In addition, $\alpha$-Syn aggregates were found to trap Rab3A and prevent its interaction with rabphilin, thus suggesting that exocytosis and neurotransmitter release are affected in Lewy body diseases (Dalfó et al., 2004). Further studies have proposed that Rab3A regulates membrane association of $\alpha$-Syn in a GTP-dependent manner (Chen et al., 2013), implying functional integration of $\alpha$-Syn into Rab proteins cycle between the cytosol and the membrane-bound state, and hence into the SV cycle (Bendor et al., 2013).

These functional interactions are further supported in a Caenorhabditis elegans model overexpressing wild type human $\alpha$ Syn which revealed that manipulating levels of Rab3A, Rab1 and Rab8A significantly rescued $\alpha$-Syn mediated loss of DA neurons (Gitler et al., 2008). Similar effects were seen in rat midbrain cultures transfected with A53T mutant $\alpha$-Syn (Gitler et al., 2008). 
$\alpha$-Syn mediated neurotoxicity was hypothesized to be caused by $\alpha$-Syn affecting transport of SV via direct interaction with the trafficking machinery (Gitler et al., 2008). Furthermore, studies in Drosophila melanogaster suggest that Rab3 is also involved in the formation of the $\mathrm{AZ}$ architecture, however the mechanisms remain unknown (Chen et al., 2015; Bae et al., 2016).

\section{The Active Zone Matrix and $\alpha$-Syn}

The docking and fusion of SVs are restricted to the active zone, demonstrating that the $\mathrm{AZ}$ is essential to translate an incoming action potential into neurotransmitter release (Figure 4; Schoch and Gundelfinger, 2006; Südhof, 2012; Wang et al., 2016). The $A Z$ is a highly conserved specialized presynaptic scaffold characterized by a dense network of proteins called AZ matrix. In mammals, this matrix includes RIM, ELKS, Munc13, Bassoon/Piccolo, Rim-BP, and Liprin- $\alpha$ (Schoch and Gundelfinger, 2006; Südhof, 2012; Wang et al., 2016). Furthermore, additional proteins are present but not restricted to the AZ, including SNAREs, ion channels, receptors, cytoskeletal proteins and adhesion molecules (Wang et al., 2016). Considering the high number of proteins constituting the AZ, it is important for this presynaptic compartment to be tightly regulated according to synaptic activity for reliable neurotransmitter release to occur (Körber and Kuner, 2016).

Although a large amount of evidence indicates that accumulation of $\alpha$-Syn at the presynaptic terminal causes reduction of proteins involved in synaptic transmission, to our knowledge, $\alpha$-Syn has not been shown to directly interact with $\mathrm{AZ}$ matrix proteins under normal conditions. In addition to that, only a few studies have explored the pathological role of $\alpha$-Syn affecting proteins associated with the AZ. Mantin and colleagues reported mice overexpressing human mutant A53T $\alpha$-Syn which showed abnormal inclusions of $\alpha$-Syn within dendrites and in the presynaptic AZ (Martin et al., 2006). Furthermore, a recent ultrastructural study by Kohl and colleagues utilized a bacterial artificial chromosome (BAC) rat model expressing full-length human SNCA gene. These transgenic rats displayed extended AZs in synapses of hippocampal CA3 neurons compared to non-transgenic animals, a phenotype that was accompanied by reduction of the postsynaptic density. However, PSD95 levels were found to be upregulated in the dentate gyrus/CA3 regions in combination with downregulation of synapsin1 and RIM3 (Kohl et al., 2016). This study suggests that $\alpha$-Syn does not only compromise the presynaptic but also postsynaptic terminals by altering both RIM3 and PSD95. The RIM protein family is an essential regulator of active zone function (Mittelstaedt et al., 2010; Südhof and Rizo, 2011). Another AZ protein called Piccolo was shown to be absent in a significant number of synaptic boutons in a model overexpressing $\alpha$-Syn (Scott et al., 2010). Piccolo along with Bassoon are specific to the vertebrate $\mathrm{AZ}$ and do appear to have a major function in guiding SVs to the $\mathrm{AZ}$ (Mukherjee et al., 2010; Südhof, 2012).

Since $\alpha$-Syn has been demonstrated to accumulate at the AZ (Martin et al., 2006), it is reasonable to hypothesize that $\mathrm{AZ}$ matrix proteins become dysfunctional over time. Moreover, $\alpha$ Syn accumulation in the AZ may jeopardize a compensatory activity of $\mathrm{AZ}$ proteins to overcome the upstream deleterious effects caused by toxic $\alpha$-Syn, such as alterations of SV pools, SNAREs, and intracellular trafficking that together lead to impaired neurotransmitter exocytosis (Larsen et al., 2006; Nemani et al., 2010; Scott et al., 2010; Janezic et al., 2013). Furthermore, the accumulation of toxic $\alpha$-Syn species in the AZ triggers the proteasome system to degrade not only $\alpha$-Syn but also AZ matrix components, the levels of which are normally regulated by proteasome activity (Wang et al., 2017).

Work carried out in Drosophila melanogaster has provided at least one mechanistic pathway by which the presynaptic $\mathrm{AZ}$ is sustained under disease-related stress (Figure 5). The maintenance of the AZ structure against activity-induced degeneration is provided by a chaperone called Drosophila nicotinamide mononucleotide adenylyltransferase (dNMNAT) (Zang et al., 2013). This neuroprotective effect is provided through NMNAT, which protects the AZ protein Bruchpilot (BRP), a homolog of mammalian ELKS/CAST proteins, from ubiquitination and subsequent degradation. However, it is not known whether high levels and/or toxic $\alpha$-Syn species, such as oligomers and fibrils, exert a toxic gain of function onto the AZ by interfering with NMNAT function (Figures 5B,C).

Unlike Drosophila that only encodes one NMNAT homolog, mammals possess three different NMNAT orthologues that are distinguishable by their differential localization within subcellular compartments (Brazill et al., 2017). NMNAT1 is a nuclear protein, NMNAT2 is localized to the Golgi apparatus and NMNAT 3 is predominantly mitochondrial (Ali et al., 2013). NMNATs are classically known for their enzymatic function of catalyzing NAD+ synthesis, which is an essential cofactor in many cellular processes including oxidative reactions and transcriptional regulation (Lau et al., 2009). NMNAT is also able to act as a molecular chaperone (reviewed in Ali et al., 2013), which is critical for neuronal homeostasis and protection against cellular stress (Ali et al., 2012; Ocampo et al., 2013; Rallis et al., 2013). However, this role does not require the enzymatic function of NMNAT, as the inactive form of dNMNAT was able to protect Drosophila photoreceptors against activity-induced degeneration (Zhai et al., 2006, 2008).

Consistent with the role of NMNAT as a neuronal maintenance factor, it has been shown that NNMAT2, which is enriched in synaptic terminals and SVs, is downregulated in several degenerative disorders. These include $\mathrm{PD}, \mathrm{AD}$, Huntington's disease (HD) and frontotemporal lobar degeneration with ubiquitin- and TDP-43-positive inclusions (FTLD-TDP) (Ali et al., 2013). NMNAT2 alterations were also found in a mouse model of tauopathy expressing mis-sense mutation P301L, found in some frontotemporal dementia and parkinsonism linked to chromosome 17 (FTDP-17) cases (Ljungberg et al., 2012). The neuroprotective effects of mammalian NMNAT2 has been explored in more detail in axonal degeneration, where loss of NMNAT2 is considered to be a physiological stimulus in severed axons and their subsequent Wallerian degeneration (Gilley and Coleman, 2010). In line with this notion, NMNAT2 overexpression was found to delay injuryinduced axonal degeneration in zebrafish (Feng et al., 2010) and to protect mice against tauopathy-induced neurodegeneration (Ljungberg et al., 2012). 


\section{Accumulated $\alpha$-Syn Affects Synaptic Vesicle Endocytosis}

In order to sustain high rates of synaptic transmission without depleting the supply of SVs, neurons have to rely on efficient endocytic recycling of SV membranes (Figure 4; Saheki and De Camilli, 2012). The synuclein family is required for SV endocytosis (Vargas et al., 2014). Using a triple synuclein KO mouse model, Vargas and colleagues demonstrated that synucleins are required for fast and efficient kinetics of early steps of SV endocytosis, membrane bending and cargo selection (Vargas et al., 2014). Fundamentally, the impaired endocytic process observed in the triple KO mouse could be re-established by individual expression of $\alpha-, \beta-$, or $\gamma$-Syn, demonstrating they are functionally redundant in the endocytic process (Vargas et al., 2014).

Rab5, which has been localized to the early endosome and is implicated in the regulation of neuronal endocytosis in association with Rabaptin-5 (Stenmark et al., 1994; Cataldo et al., 2000), appears to play a role in the internalization of exogenous $\alpha$-Syn. Overexpression of constitutively active Rab5 or its effector Rabaptin-5 in cultured neurons lead to the formation of intracellular inclusions resembling Lewy bodies (Sung et al., 2001). More recently, a study revealed that high levels of $\alpha$-Syn promotes its interaction with dynein, a retrograde motor protein, inducing a significant increase in activated levels of Rab5 and Rab7, both key regulators of the endocytic process (Fang et al., 2017).

Under intense electric stimulation, overexpression of wild type $\alpha$-Syn in lamprey nerve terminals caused loss of SVs and an expanded plasma membrane which pointed toward impaired vesicle recycling (Busch et al., 2014). However, this endocytic deficit was not observed when low stimulation was applied. Interestingly, overexpression of mutant A30P $\alpha$-Syn, with a disrupted $\mathrm{N}$-terminal that greatly impairs its binding to phospholipids and disrupt the $\alpha$-helical conformation, showed very little effect on vesicle recycling. Therefore, Busch and colleagues concluded that synaptic endocytic failure could only be visualized when high synaptic activity is in place and under proper folding of $\alpha$-Syn $\mathrm{N}$-terminal $\alpha$-helix (Busch et al., 2014). Corroborating these findings, overexpression of mutant human A53T $\alpha$-Syn, but not A30P $\alpha$-Syn, at the calyx of Held terminals in mice was also shown to cause impairment of slow and rapid endocytosis, and restoration of the RRP (Xu et al., 2016). These studies endorse the role of $\alpha$ Syn in membrane curvature formation and stabilization, and consequently for endocytosis (Pranke et al., 2011; Busch et al., 2014).

\section{$\alpha$-Syn Related Presynaptic Deficits Converge in Dopaminergic Neurons}

Under physiological conditions, native soluble $\alpha$-Syn is involved in several steps in the presynaptic terminal that are required to trigger exocytosis upon activation by an action potential (Burré, 2015). However, these steps are not exclusively regulated by $\alpha$-Syn. Under pathological conditions, the presence of toxic $\alpha$-Syn species such as oligomers and amyloid fibrils, triggers the misregulation of several synaptic proteins (Table 1), leading to functional impairment of the presynaptic terminal in both animal models and PD patients (Figure 5). These alterations at the presynapse have been shown to be progressive and selective to dopaminergic neurons, at least in mouse models (Volpicelli-Daley et al., 2011; Janezic et al., 2013). Thus, upon $\alpha$-Syn accumulation, DA neurons show reduced firing rates, a phenotype that positively correlates with behavior impairment, ultimately followed by degeneration of these neurons (Janezic et al., 2013).

A similar sequence of events whereby presynaptic deficits precede neuronal loss are also recapitulated in induced pluripotent stem cells (iPSCs) derived from PD patients that harbor the A53T $\alpha$-Syn mutation. Kouroupi and colleagues observed a significant downregulation of genes coding for presynptic proteins in comparison to controls (Kouroupi et al., 2017). Strikingly, A53T $\alpha$-Syn iPSCs cells exhibited thinner, less fasciculated neuronal processes that were accompanied by a $27 \%$ reduction in the number of synaptic contacts. The deleterious effects caused by overexpression of human $\alpha$-Syn were also observed in Drosophila which identified reduced synaptic connectivity between DA neurons and Kenyon cells even before the onset of motor abnormalities (Riemensperger et al., 2013).

Together this data suggests that there is a potential direct association, between $\alpha$-Syn accumulation and dopamine metabolism, which in turn makes DA neurons especially vulnerable to cellular stress and subsequent neurodegeneration. Indeed, several recent findings support this hypothesis, which could shed light onto the pathogenic mechanisms underlying DA neuron-specific cell death in PD.

\section{$\alpha$-SYN AND DOPAMINE: A DANGEROUS LIAISON}

The loss of dopaminergic neurons in the substantia nigra along with $\alpha$-Syn enriched Lewy body inclusions are the main histopathological hallmarks of PD (Lees et al., 2009). DA neurons are thought to be the most vulnerable cell type in $\mathrm{PD}$, which led to several hypotheses attempting to explain the underlying mechanisms. One of these is related to the high-energy requirement of DA neurons due to their poorly myelinated axonal arborisation which is orders of magnitude larger than any other neuronal cell type (Pissadaki and Bolam, 2013). This hypothesis predicts that any disturbance inducing a negative energy balance would be especially dangerous to DA neurons, placing them at high risk in case of energy failure, such as mitochondrial dysfunction, which has been shown to play an important role in PD (Lin and Beal, 2006).

Although energy balance contributes to the vulnerability of DA neurons, regulation of dopamine levels at the synaptic terminals is thought to be vital for DA neuron susceptibility observed in PD (Lotharius and Brundin, 2002b). Accordingly, $\alpha$-Syn has been implicated as a key regulator of dopamine homeostasis (Abeliovich et al., 2000; Venda et al., 2010). The activity of the rate-limiting enzyme tyrosine hydroxylase 
(TH) responsible for producing dopamine through conversion of L-tyrosine to L-3,4-dihydroxyphenylalanine (L-DOPA), is negatively regulated by increased concentration of $\alpha$-Syn in vitro (Perez et al., 2002). As a result, reduced levels of dopamine were observed in cell culture transfected with A53T mutant $\alpha$-Syn (Perez et al., 2002).

In line with these findings, reduced $\mathrm{TH}$ activity was found in mouse models overexpressing $\alpha$-Syn (Masliah et al., 2000; Kirik et al., 2002). Mechanistically, $\alpha$-Syn decreases TH activity by reducing its phosphorylation in vitro (Perez et al., 2002; Peng et al., 2005) as TH is activated by phosphorylation of seryl residues in the $\mathrm{TH}$ regulatory domain (Alerte et al., 2008). In turn, by silencing $\alpha$-Syn in MN9D cells, increased TH activity and dopamine biosynthesis were observed (Liu et al., 2008). In addition to the ability of $\alpha$-Syn to regulate TH activity, work performed by Tehranian and colleagues demonstrated that $\alpha$-Syn can interact with L-aromatic amino acid decarboxylase (AADC) and can reduce its activity (Tehranian et al., 2006). AADC acts in the last step of dopamine synthesis by converting L-DOPA to dopamine (Tehranian et al., 2006).

$\alpha$-Syn does not only modulate the activity of enzymes responsible for dopamine synthesis, but it also impairs transport and uptake of dopamine by altering the activity of the vesicular monoamine transporter 2 (VMAT2) and the dopamine transporter (DAT), respectively. VMAT2 is responsible for dopamine uptake from the cytoplasm into SV (Lotharius and Brundin, 2002b). DAT transports dopamine from the synaptic cleft back into the cytoplasm is the primary mechanism and possibly the most important regulator of extracellular dopamine concentrations (Vaughan and Foster, 2013). Lundblad and colleagues showed that unilateral overexpression of human wild type $\alpha$-Syn in the $\mathrm{SN}$ of adult rats caused $50 \%$ reduction in dopamine reuptake without axonal damage 10 days after exposure (Lundblad et al., 2012). Over time, dopamine reuptake was further decreased in the striatum, followed by axonal swelling and dystrophic axons in the presence of $\alpha$-Syn aggregates and a profound $70 \%$ reduction in dopamine release upon chemical pulse with potassium chloride (Lundblad et al., 2012). Additionally, $\alpha$-Syn was shown to interact with DAT and in turn to form complexes via the carboxyl-terminal tail of DAT and the NAC domain of $\alpha$-Syn (Lee et al., 2001). This interaction and complex formation reduced DAT activity due to impairment of dopamine reuptake from the synaptic cleft (Wersinger and Sidhu, 2003; Wersinger et al., 2003), suggesting that $\alpha$-Syn accumulation causes a vicious cycle of impaired VMAT2 and DAT function.

Consistent with this notion, Bellucci et al. showed that mice expressing the truncated $\alpha$-syn120 exhibited marked redistribution of DAT/ $\alpha$-Syn complexes in the striatum and the SN (Bellucci et al., 2011). These findings suggest that $\alpha$-Syn acts as a synaptic modulator of DA in early PD pathogenesis by regulating the subcellular distribution of key proteins such as DAT (Bellucci et al., 2011). DAT has also been reported to be absent in the putamen of $\mathrm{PD}$ patients (Seeman and Niznik, 1990). Interestingly, VMAT2 was shown to be incorporated into Lewy bodies of SN neurons in PD patients (Yamamoto et al., 2006). Moreover, profound defects in
VMAT2 were also observed in synaptic vesicles isolated from post-mortem brain tissue of PD patients, including reduction in vesicular uptake and the binding ability of VMAT2 (Pifl et al., 2014). These findings are in agreement with previous studies showing that increased levels of $\alpha$-Syn inhibit VMAT2 activity, ultimately increasing cytosolic levels of dopamine (Guo et al., 2008). As a consequence, dysregulation of dopamine transport caused by impaired DAT and VMAT2 activity will lead to altered levels of dopamine (Lotharius and Brundin, 2002b; Nutt et al., 2004). Dopamine by itself is a risk factor for dopaminergic neurodegeneration; it is highly sensitive to spontaneous degradation and to produce quinone as well as other reactive oxygen species until it is sequestered into vesicles (Lotharius and Brundin, 2002a,b; Xu et al., 2002; Caudle et al., 2007).

This data suggests an intricate and potentially direct interplay between $\alpha$-Syn and dopamine that directly contributes to functional deficits of DA neurons. In support of this, Mor et al. recently demonstrated that dopamine promotes $\alpha$ Syn oligomerisation in vivo and that disrupting the ability of dopamine to stabilize or modify $\alpha$-Syn oligomers was sufficient to rescue dopamine-mediated toxicity (Mor et al., 2017). These results recapitulate in vitro data revealing the ability of dopamine to trigger formation of $\alpha$-Syn oligomers (Choi et al., 2013). This cooperative toxicity of $\alpha$-Syn and dopamine was also recapitulated in C. elegans (Mor et al., 2017). Furthermore, a corresponding mouse model revealed early mild synaptic defects in the striatum without degeneration of cell bodies; however, by 5 months post-injection, the mice exhibit a severe loss of dopaminergic nerve terminals $(-62 \%$ VMAT2 and $-55 \%$ DAT) as compared to only $25 \%$ loss of dopaminergic neurons (Mor et al., 2017). These results reinforce the hypothesis that $\alpha$-Syn mediated early dopamine imbalance at synaptic terminals is the initiating event which in turn triggers synaptic and axonal dysfunction, subsequently leading to degeneration of nigrostriatal pathways and DA neuron-specific cell death.

\section{CONCLUSIONS}

Studies in PD-related animal models and post-mortem patient material demonstrate that soluble oligomers and aggregating protofibrils of $\alpha$-Syn accumulate in synapses and axons prior to the onset of disease symptoms. These accumulating toxic $\alpha$-Syn species impair synaptic compartments and presynaptic processes required for neuronal communication, including maintenance of SV pools, SV trafficking, tethering, docking, priming and fusion of SV within the plasma membrane at the active zone. The resulting synaptopathy phenotypes manifest prior to dopaminergic neurodegeneration, hence reinforcing the hypothesis that onset and evolution of PD progress in a dying back-like manner, from initial dysfunction at the synapse and impairing axonal connections, to eventual neuronal cell body death. Although $\alpha$-Syn is expressed throughout the brain and enriched at presynaptic terminals, DA neurons are most susceptible to toxic effects exerted by accumulating and 
dysfunctional $\alpha$-Syn. This fatal attraction is likely related to $\alpha$-Syn regulating dopamine levels in two distinct manners. First, $\alpha$-Syn is a negative modulator of dopamine synthesis by interplay with the rate-limiting enzyme $\mathrm{TH}$ and AADC. Second, $\alpha$-Syn disrupts VMAT2 and DAT activity and their function in regulating dopamine levels in the synaptic terminal. In turn, dysregulated dopamine levels fuel the formation of soluble $\alpha$-Syn oligomers that are considered to be the most toxic species. This fatal interplay and its ensuing vicious cycle of dopamine and $\alpha$-Syn interference is likely the starting point driving synaptic dysfunction and impaired neuronal communication observed in the early, prodromal stages of PD.

\section{REFERENCES}

Abeliovich, A., and Gitler, A. D. (2016). Defects in trafficking bridge Parkinson's disease pathology and genetics. Nature 539, 207-216. doi: 10.1038/nature20414

Abeliovich, A., Schmitz, Y., Fariñas, I., Choi-Lundberg, D., Ho, W.-H., Castillo, P. E., et al. (2000). Mice Lacking $\alpha$-Synuclein Display Functional Deficits in the Nigrostriatal Dopamine System. Neuron 25, 239-252. doi: 10.1016/S0896-6273(00)80886-7

Alabi, A. A., and Tsien, R. W. (2012). Synaptic vesicle pools and dynamics. Cold Spring Harb. Perspect. Biol. 4:a013680. doi: 10.1101/cshperspect.a013680

Alerte, T. N. M., Akinfolarin, A. A., Friedrich, E. E., Mader, S. A., Hong, C.-S., and Perez, R. G. (2008). Alpha-synuclein aggregation alters tyrosine hydroxylase phosphorylation and immunoreactivity: lessons from viral transduction of knockout mice. Neurosci. Lett. 435, 24-29. doi: 10.1016/j.neulet.2008.02.014

Ali, Y. O., Li-Kroeger, D., Bellen, H. J., Zhai, R. G., and Lu, H. C. (2013). NMNATs, evolutionarily conserved neuronal maintenance factors. Trends Neurosci. 36, 632-640. doi: 10.1016/j.tins.2013.07.002

Ali, Y. O., Ruan, K., and Zhai, R. G. (2012). NMNAT suppresses Tau-induced neurodegeneration by promoting clearance of hyperphosphorylated Tau oligomers in a Drosophila model of tauopathy. Hum. Mol. Genet. 21, 237-250. doi: $10.1093 / \mathrm{hmg} / \mathrm{ddr} 449$

Appel-Cresswell, S., Vilarino-Guell, C., Encarnacion, M., Sherman, H., Yu, I., Shah, B., et al. (2013). Alpha-synuclein p.H50Q, a novel pathogenic mutation for Parkinson's disease. Mov. Disord. 28, 811-813. doi: 10.1002/mds. 25421

Babcock, D. T., and Ganetzky, B. (2015). Transcellular spreading of huntingtin aggregates in the Drosophila brain. Proc. Natl. Acad. Sci. U.S.A. 112, E5427E5433. doi: 10.1073/pnas.1516217112

Bae, H., Chen, S., Roche, J. P., Ai, M., Wu, C., Diantonio, A., et al. (2016). Rab3GEF Controls Active Zone Development at the Drosophila neuromuscular junction. eNeuro 3, 1-18. doi: 10.1523/ENEURO.0031-16.2016

Bae, J. R., and Kim, S. H. (2017). Synapses in neurodegenerative diseases. BMB Rep. 50, 237-246. doi: 10.5483/BMBRep.2017.50.5.038

Bellucci, A., Navarria, L., Falarti, E., Zaltieri, M., Bono, F., Collo, G., et al. (2011). Redistribution of DAT/ $\alpha$-synuclein complexes visualized by "in situ" proximity ligation assay in transgenic mice modelling early Parkinson's disease. PLoS ONE 6:27959. doi: 10.1371/journal.pone.0027959

Bendor, J. T., Logan, T. P., and Edwards, R. H. (2013). The function of $\alpha$-synuclein. Neuron 79, 1044-1066. doi: 10.1016/j.neuron.2013.09.004

Bennett, M. C., Bishop, J. F., Leng, Y., Chock, P. B., Chase, T. N., and Mouradian, M. M. (1999). Degradation of $\alpha$-synuclein by proteasome. J. Biol. Chem. 274, 33855-33858. doi: 10.1074/jbc.274.48.33855

Bereczki, E., Branca, R. M., Francis, P. T., Pereira, J. B., Baek, J.-H., Hortobágyi, T., et al. (2018). Synaptic markers of cognitive decline in neurodegenerative diseases: a proteomic approach. Brain 141, 582-595. doi: 10.1093/brain/awx352

Bereczki, E., Francis, P. T., Howlett, D., Pereira, J. B., Höglund, K., Bogstedt, A., et al. (2016). Synaptic proteins predict cognitive decline in Alzheimer's disease and Lewy body dementia. Alzheimer Dement. 12, 1149-1158. doi: 10.1016/j.jalz.2016.04.005

\section{AUTHOR CONTRIBUTIONS}

All authors listed have made a substantial, direct and intellectual contribution to the work, and approved it for publication.

\section{ACKNOWLEDGMENTS}

We thank D. P. Srivastava, R. B. Parsons, D. Aarsland, A. Perry, and W. H. Au for comments on the manuscript and B. Kottler for helpful suggestions. This work was supported by a $\mathrm{PhD}$ fellowship from CAPES Foundation-Ministry of Education of Brazil to JCB and by the UK Medical Research Council (G0701498; MR/L010666/1) to FH.

Binotti, B., Jahn, R., and Chua, J. J. E. (2016). Functions of rab proteins at presynaptic sites. Cells 5:7. doi: 10.3390/cells5010007

Braak, H., Del Tredici, K., Rüb, U., De Vos, R. A. I., Jansen Steur, E. N. H., and Braak, E. (2003). Staging of brain pathology related to sporadic Parkinson's disease. Neurobiol. Aging 24, 197-211. doi: 10.1016/S0197-4580(02)00065-9

Braak, H., Sandmann-Keil, D., Gai, W., and Braak, E. (1999). Extensive axonal Lewy neurites in Parkinson's disease: a novel pathological feature revealed by alpha-synuclein immunocytochemistry. Neurosci. Lett. 265, 67-69. doi: 10.1016/S0304-3940(99)00208-6

Brazill, J. M., Li, C., Zhu, Y., Zhai, R. G., Bonini, N., Lee, E., et al. (2017). NMNAT: it's an NAD+ synthase... It's a chaperone... It's a neuroprotector. Curr. Opin. Genet. Dev. 44, 156-162. doi: 10.1016/j.gde.2017.03.014

Brose, N., O'Connor, V., and Skehel, P. (2010). Synaptopathy: dysfunction of synaptic function? Biochem. Soc. Trans. 38, 443-444. doi: 10.1042/BST0 380443

Burke, R. E., and O’Malley, K. (2013). Axon degeneration in Parkinson's disease. Exp. Neurol. 246, 72-83. doi: 10.1016/j.expneurol.2012.01.011

Burré, J. (2015). The synaptic function of $\alpha$-synuclein. J. Parkinsons Dis. 5, 699-713. doi: 10.3233/JPD-150642

Burré, J., Sharma, M., Tsetsenis, T., Buchman, V., Etherton, M. R., and Südhof, T. C. (2010). Alpha-synuclein promotes SNARE-complex assembly in vivo and in vitro. Science 329, 1663-1667. doi: 10.1126/science.1195227

Busch, D. J., Oliphint, P. A., Walsh, R. B., Banks, S. M. L., Woods, W. S., George, J. M., et al. (2014). Acute increase of $\alpha$-synuclein inhibits synaptic vesicle recycling evoked during intense stimulation. Mol. Biol. Cell 25, 3926-3941. doi: $10.1091 / \mathrm{mbc}$.E14-02-0708

Cabin, D. E., Shimazu, K., Murphy, D., Cole, N. B., Gottschalk, W., McIlwain, K. L., et al. (2002). Synaptic vesicle depletion correlates with attenuated synaptic responses to prolonged repetitive stimulation in mice lacking alpha-synuclein. J. Neurosci. 22, 8797-807.

Calo, L., Wegrzynowicz, M., Santivañez-Perez, J., and Grazia Spillantini, M. (2016). Synaptic failure and a-synuclein. Mov. Disord. 31, 169-177. doi: $10.1002 / \mathrm{mds} .26479$

Caminiti, S. P., Presotto, L., Baroncini, D., Garibotto, V., Moresco, R. M., Gianolli, L., et al. (2017). Axonal damage and loss of connectivity in nigrostriatal and mesolimbic dopamine pathways in early Parkinson's disease. Neuroimage Clin. 14, 734-740. doi: 10.1016/j.nicl.2017.03.011

Cataldo, A. M., Peterhoff, C. M., Troncoso, J. C., Gomez-Isla, T., Hyman, B. T., and Nixon, R. A. (2000). Endocytic pathway abnormalities precede amyloid $\beta$ deposition in sporadic Alzheimer's disease and down syndrome. Am. J. Pathol. 157, 277-286. doi: 10.1016/S0002-9440(10)64538-5

Caudle, W. M., Richardson, J. R., Wang, M. Z., Taylor, T. N., Guillot, T. S., McCormack, A. L., et al. (2007). Reduced vesicular storage of dopamine causes progressive nigrostriatal neurodegeneration. J. Neurosci. 27, 8138-8148. doi: 10.1523/JNEUROSCI.0319-07.2007

Chandra, S., Gallardo, G., Fernández-Chacón, R., Schlüter, O. M., and Südhof, T. C. (2005). $\alpha$-Synuclein cooperates with CSP $\alpha$ in preventing neurodegeneration. Cell 123, 383-396. doi: 10.1016/j.cell.2005.09.028 
Chen, R. H. C., Wislet-Gendebien, S., Samuel, F., Visanji, N. P., Zhang, G., Marsilio, D., et al. (2013). Alpha-Synuclein membrane association is regulated by the Rab3a recycling machinery and presynaptic activity. J. Biol. Chem. 288, 7438-7449. doi: 10.1074/jbc.M112.439497

Chen, S., Gendelman, H. K., Roche, J. P., Alsharif, P., and Graf, E. R. (2015). Mutational analysis of Rab3 function for controlling active zone protein composition at the Drosophila neuromuscular junction. PLoS ONE 10:136938. doi: 10.1371/journal.pone.0136938

Cheng, H. C., Ulane, C. M., and Burke, R. E. (2010). Clinical progression in Parkinson disease and the neurobiology of axons. Ann. Neurol. 67, 715-725. doi: 10.1002/ana.21995

Choi, B.-K., Choi, M.-G., Kim, J.-Y., Yang, Y., Lai, Y., Kweon, D.-H., et al. (2013). Large $\alpha$-synuclein oligomers inhibit neuronal SNAREmediated vesicle docking. Proc. Natl. Acad. Sci. U.S.A. 110, 4087-4092. doi: 10.1073/pnas.1218424110

Chung, C. Y., Koprich, J. B., Siddiqi, H., and Isacson, O. (2009). Dynamic changes in presynaptic and axonal transport proteins combined with striatal neuroinflammation precede dopaminergic neuronal loss in a rat model of AAV -synucleinopathy. J. Neurosci. 29, 3365-3373. doi: 10.1523/JNEUROSCI.5427-08.2009

Chutna, O., Gonçalves, S., Villar-Piqué, A., Guerreiro, P., Marijanovic, Z., Mendes, T., et al. (2014). The small GTPase Rab11 co-localizes with $\alpha$-synuclein in intracellular inclusions and modulates its aggregation, secretion and toxicity. Hum. Mol. Genet. 23, 6732-6745. doi: 10.1093/hmg/ddu391

Conway, K. A., Lee, S.-J., Rochet, J.-C., Ding, T. T., Williamson, R. E., and Lansbury, P. T. (2000). Acceleration of oligomerization, not fibrillization, is a shared property of both alpha -synuclein mutations linked to early-onset Parkinson's disease: implications for pathogenesis and therapy. Proc. Natl. Acad. Sci. U.S.A. 97, 571-576. doi: 10.1073/pnas. 97.2.571

Cuervo, A. M., Stafanis, L., Fredenburg, R., Lansbury, P. T., and Sulzer, D. (2004). Impaired degradation of mutant $\alpha$-synuclein by chaperone-mediated autophagy. Science 305, 1292-1295. doi: 10.1126/science.1101738

Dalfó, E., Barrachina, M., Rosa, J. L., Ambrosio, S., and Ferrer, I. (2004). Abnormal $\alpha$-synuclein interactions with rab3a and rabphilin in diffuse Lewy body disease. Neurobiol. Dis. 16, 92-97. doi: 10.1016/j.nbd.2004.01.001

Diao, J., Burré, J., Vivona, S., Cipriano, D. J., Sharma, M., Kyoung, M., et al. (2013). Native $\alpha$-synuclein induces clustering of synaptic-vesicle mimics via binding to phospholipids and synaptobrevin-2/VAMP2. eLife 2013, 996-1004. doi: 10.7554/eLife.00592

Dijkstra, A. A., Ingrassia, A., de Menezes, R. X., van Kesteren, R. E., Rozemuller, A. J. M., Heutink, P., et al. (2015). Evidence for immune response, axonal dysfunction and reduced endocytosis in the substantia nigra in early stage Parkinson's disease. PLoS ONE 10:e0128651. doi: 10.1371/journal.pone.0128651

Duda, J. E., Giasson, B. I., Mabon, M. E., Lee, V. M. Y., and Trojanowski, J. Q. (2002). Novel antibodies to synuclein show abundant striatal pathology in Lewy body diseases. Ann. Neurol. 52, 205-210. doi: 10.1002/ana.10279

Dulubova, I., Lou, X., Lu, J., Huryeva, I., Alam, A., Schneggenburger, R., et al. (2005). A Munc13/RIM/Rab3 tripartite complex: from priming to plasticity? EMBO J. 24, 2839-2850. doi: 10.1038/sj.emboj.7600753

Dutta, D., Heo, I., and Clevers, H. (2017). Disease modeling in stem cell-derived 3D organoid systems. Trends Mol. Med. 23, 393-410. doi: 10.1016/j.molmed.2017.02.007

Exner, N., Lutz, A. K., Haass, C., and Winklhofer, K. F. (2012). Mitochondrial dysfunction in Parkinson's disease: molecular mechanisms and pathophysiological consequences. EMBO J. 31, 3038-3062. doi: 10.1038/emboj.2012.170

Fang, F., Yang, W., Florio, J. B., Rockenstein, E., Spencer, B., Orain, X. M., et al. (2017). Synuclein impairs trafficking and signaling of BDNF in a mouse model of Parkinson's disease. Sci. Rep. 7:3868. doi: 10.1038/s41598-017-04232-4

Farrer, M., Kachergus, J., Forno, L., Lincoln, S., Wang, D. S., Hulihan, M., et al. (2004). Comparison of Kindreds with Parkinsonism and $\alpha$-Synuclein Genomic Multiplications. Ann. Neurol. 55, 174-179. doi: 10.1002/ana.10846

Feng, Y., Yan, T., Zheng, J., Ge, X., Mu, Y., Zhang, Y., et al. (2010). Overexpression of WldS or Nmnat2 in mauthner cells by single-cell electroporation delays axon degeneration in live zebrafish. J. Neurosci. Res. 88, 3319-3327. doi: $10.1002 /$ jnr.22498
Ferreira, M., and Massano, J. (2017). An updated review of Parkinson's disease genetics and clinicopathological correlations. Acta Neurol. Scand. 135, 273-284. doi: 10.1111/ane. 12616

Frost, B., and Diamond, M. I. (2009). Prion-like mechanisms in neurodegenerative diseases. Nat. Rev. Neurosci. 11, 155-159. doi: 10.1038/nrn2786

Galvin, J. E., Uryu, K., Lee, V. M.-Y., and Trojanowski, J. Q. (1999). Axon pathology in Parkinson's disease and Lewy body dementia hippocampus contains alpha -, beta -, and gamma -synuclein. Proc. Natl. Acad. Sci. U.S.A. 96, 13450-13455. doi: 10.1073/pnas.96.23.13450

Games, D., Valera, E., Spencer, B., Rockenstein, E., Mante, M., Adame, A., et al. (2014). Reducing C-terminal-truncated alpha-synuclein by immunotherapy attenuates neurodegeneration and propagation in Parkinson's disease-like models. J. Neurosci. 34, 9441-9454. doi: 10.1523/JNEUROSCI.5314-13.2014

Gan-Or, Z., Dion, P. A., and Rouleau, G. A. (2015). Genetic perspective on the role of the autophagy-lysosome pathway in Parkinson disease. Autophagy 11, 1443-1457. doi: 10.1080/15548627.2015.1067364

Garcia-Reitböck, P., Anichtchik, O., Bellucci, A., Iovino, M., Ballini, C., Fineberg, E., et al. (2010). SNARE protein redistribution and synaptic failure in a transgenic mouse model of Parkinson's disease. Brain 133, 2032-2044. doi: 10.1093/brain/awq132

Giasson, B. I., Murray, I. V. J., Trojanowski, J. Q., and Lee, V. M. Y. (2001) A hydrophobic stretch of 12 amino acid residues in the middle of alphasynuclein is essential for filament assembly. J. Biol. Chem. 276, 2380-2386. doi: 10.1074/jbc.M008919200

Gilley, J., and Coleman, M. P. (2010). Endogenous Nmnat2 is an essential survival factor for maintenance of healthy axons. PLoS Biol. 8:e1000300. doi: 10.1371/journal.pbio.1000300

Gitler, A. D., Bevis, B. J., Shorter, J., Strathearn, K. E., Hamamichi, S., Su, L. J., et al. (2008). The Parkinson's disease protein alpha-synuclein disrupts cellular Rab homeostasis. Proc. Natl. Acad. Sci. U.S.A. 105, 145-150. doi: 10.1073/pnas.0710685105

Goedert, M. (2001). Alpha-synuclein and neurodegenerative diseases. Nat. Rev. Neurosci. 2, 492-501. doi: 10.1038/35081564

Goedert, M. (2015). Alzheimer's and Parkinson's diseases: the prion concept in relation to assembled A, tau, and $\alpha$-synuclein. Science 349:1255555. doi: $10.1126 /$ science. 1255555

Goedert, M., Jakes, R., and Spillantini, M. G. (2017). The Synucleinopathies: twenty years on. J. Parkinsons. Dis. 7, S53-S71. doi: 10.3233/JPD-179005

Gonçalves, S. A., Macedo, D., Raquel, H., Simões, P. D., Giorgini, F., Ramalho, J. S., et al. (2016). shRNA-based screen identifies endocytic recycling pathway components that act as genetic modifiers of alphasynuclein aggregation, secretion and toxicity. PLoS Genet. 12:e1005995. doi: 10.1371/journal.pgen.1005995

Grosch, J., Winkler, J., and Kohl, Z. (2016). Early degeneration of both dopaminergic and serotonergic axons - a common mechanism in Parkinson's disease. Front. Cell. Neurosci. 10:293. doi: 10.3389/fncel.2016.00293

Gross, O. P., and von Gersdorff, H. (2016). Recycling at synapses. Elife 5:e17692. doi: 10.7554/eLife.17692

Guo, J. L., and Lee, V. M. Y. (2014). Cell-to-cell transmission of pathogenic proteins in neurodegenerative diseases. Nat. Med. 20, 130-138. doi: $10.1038 / \mathrm{nm} .3457$

Guo, J. T., Chen, A. Q., Kong, Q., Zhu, H., Ma, C. M., and Qin, C. (2008). Inhibition of vesicular monoamine transporter-2 activity in $\alpha$-synuclein stably transfected SH-SY5Y cells. Cell. Mol. Neurobiol. 28, 35-47. doi: 10.1007/s10571-007-9227-0

Hardy, J. (2010). Genetic analysis of pathways to parkinson disease. Neuron 68, 201-206. doi: 10.1016/j.neuron.2010.10.014

Hawkes, C. H., Del Tredici, K., and Braak, H. (2010). A timeline for Parkinson's disease. Park. Relat. Disord. 16, 79-84. doi: 10.1016/j.parkreldis.2009.08.007

Hornykiewicz, O. (1998). Biochemical aspects of Parkinson's disease. Neurology 51, S2-9. doi: 10.1212/WNL.51.2_SUPPL_2.S2

Ingelsson, M. (2016). Alpha-synuclein oligomers - neurotoxic molecules in Parkinson's disease and other lewy body disorders. Front. Neurosci. 10:408 doi: 10.3389/fnins.2016.00408

Jakes, R., Spillantini, M. G., and Goedert, M. (1994). Identification of two distinct synucleins from human brain. FEBS Lett. 345, 27-32. doi: 10.1016/0014-5793(94)00395-5

Janezic, S., Threlfell, S., Dodson, P. D., Dowie, M. J., Taylor, T. N., Potgieter, D., et al. (2013). Deficits in dopaminergic transmission precede neuron loss 
and dysfunction in a new Parkinson model. Proc. Natl. Acad. Sci. U.S.A. 110, E4016-E4025. doi: 10.1073/pnas.1309143110

Jensen, M. B., Bhatia, V. K., Jao, C. C., Rasmussen, J. E., Pedersen, S. L., Jensen, K. J., et al. (2011). Membrane curvature sensing by amphipathic helices: a single liposome study using $\alpha$-synuclein and annexin B12. J. Biol. Chem. 286, 42603-42614. doi: 10.1074/jbc.M111.271130

Jucker, M., and Walker, L. C. (2013). Self-propagation of pathogenic protein aggregates in neurodegenerative diseases. Nature 501, 45-51. doi: $10.1038 /$ nature 12481

Kahle, P. J., Neumann, M., Ozmen, L., Muller, V., Jacobsen, H., Schindzielorz, A., et al. (2000). Subcellular localization of wild-type and Parkinson's diseaseassociated mutant alpha-synuclein in human and transgenic mouse brain. $J$. Neurosci. 20, 6365-6373.

Kalia, L. V., and Lang, A. E. (2015). Parkinson's disease. Lancet 6736, 1-17. doi: 10.1016/S0140-6736(14)61393-3

Katz, B. (1969). The Release of Neural Transmitter Substances. Liverpool: Liverpool University Press.

Keane, P. C., Kurzawa, M., Blain, P. G., and Morris, C. M. (2011). Mitochondrial dysfunction in Parkinson's disease. Parkinsons Dis. 2011:716871. doi: 10.4061/2011/716871

Kelly, E. E., Horgan, C. P., Goud, B., McCaffrey, M. W., Colicelli, J., Wennerberg, K., et al. (2012). The Rab family of proteins: 25 years on. Biochem. Soc. Trans. 40, 1337-1347. doi: 10.1042/BST20120203

Kirik, D., Rosenblad, C., Burger, C., Lundberg, C., Johansen, T. E., Muzyczka, N., et al. (2002). Parkinson-like neurodegeneration induced by targeted overexpression of $\alpha$-synuclein in the nigrostriatal system. J. Neurosci. 22, 2780-2791.

Klein, C., and Westenberger, A. (2012). Genetics of Parkinson's disease. Cold Spring Harb. Perspect. Med. 2:a008888. doi: 10.1101/cshperspect.a008888

Kohl, Z., Ben Abdallah, N., Vogelgsang, J., Tischer, L., Deusser, J., Amato, D., et al. (2016). Severely impaired hippocampal neurogenesis associates with an early serotonergic deficit in a BAC $\alpha$-synuclein transgenic rat model of Parkinson's disease. Neurobiol. Dis. 85, 206-217. doi: 10.1016/j.nbd.2015.10.021

Körber, C., and Kuner, T. (2016). Molecular machines regulating the release probability of synaptic vesicles at the active zone. Front. Synaptic Neurosci. 8:5. doi: 10.3389/fnsyn.2016.00005

Kouroupi, G., Taoufik, E., Vlachos, I. S., Tsioras, K., Antoniou, N., Papastefanaki, F., et al. (2017). Defective synaptic connectivity and axonal neuropathology in a human iPSC-based model of familial Parkinson's disease. Proc. Natl. Acad. Sci. U.S.A. 114, E3679-E3688. doi: 10.1073/pnas.1617259114

Kramer, M. L., and Schulz-Schaeffer, W. J. (2007). Presynaptic alpha-synuclein aggregates, not Lewy bodies, cause neurodegeneration in dementia with Lewy bodies. J. Neurosci. 27, 1405-1410. doi: 10.1523/JNEUROSCI.4564-06.2007

Krüger, R., Kuhn, W., Müller, T., Woitalla, D., Graeber, M., Kösel, S., et al. (1998). Ala30Pro mutation in the gene encoding alpha-synuclein in Parkinson's disease. Nat. Genet. 18, 106-108. doi: 10.1038/ng0298-106

Lai, Y., Kim, S., Varkey, J., Lou, X., Song, J. K., Diao, J., et al. (2014). Nonaggregated $\alpha$-synuclein influences snare-dependent vesicle docking via membrane binding. Biochemistry 53, 3889-3896. doi: 10.1021/bi5002536

Lang, A. E., and Lozano, A. M. (1998a). Parkinson's Disease - First of two parts. N. Engl. J. Med. 339, 1044-1053. doi: 10.1056/NEJM199810083391506

Lang, A. E., and Lozano, A. M. (1998b). Parkinson's Disease - Second of two parts. N. Engl. J. Med. 339, 1130-1143. doi: 10.1056/NEJM199810153391607

Larsen, K. E., Schmitz, Y., Troyer, M. D., Mosharov, E., Dietrich, P., Quazi, A. Z., et al. (2006). Alpha-synuclein overexpression in PC12 and chromaffin cells impairs catecholamine release by interfering with a late step in exocytosis. J. Neurosci. 26, 11915-11922. doi: 10.1523/JNEUROSCI.3821-06.2006

Lashuel, H., a, Overk, C. R., Oueslati, A., and Masliah, E. (2013). The many faces of $\alpha$-synuclein: from structure and toxicity to therapeutic target. Nat. Rev. Neurosci. 14, 38-48. doi: 10.1038/nrn3406

Lau, C., Niere, M., and Ziegler, M. (2009). The NMN/NaMN adenylyltransferase (NMNAT) protein family. Front. Biosci. (Landmark Ed.) 14, 410-431. doi: $10.2741 / 3252$

Lee, F. J., Liu, F., Pristupa, Z. B., and Niznik, H. B. (2001). Direct binding and functional coupling of alpha-synuclein to the dopamine transporters accelerate dopamine-induced apoptosis. FASEB J. 15, 916-926. doi: 10.1096/fj.00-0334com
Lee, S. J., Jeon, H., and Kandror, K. V. (2008). Alpha-Synuclein is localized in a subpopulation of rat brain synaptic vesicles. Acta Neurobiol. Exp. (Wars). 68, 509-515.

Lees, A. J., Hardy, J., and Revesz, T. (2009). Parkinson's disease. Lancet 373, 2055-2066. doi: 10.1016/S0140-6736(09)60492-X

Lepeta, K., Lourenco, M. V., Schweitzer, B. C., Martino Adami, P. V., Banerjee, P., Catuara-Solarz, S., et al. (2016). Synaptopathies: synaptic dysfunction in neurological disorders-A review from students to students. J. Neurochem. 785-805. doi: 10.1111/jnc.13713

Lesage, S., Anheim, M., Letournel, F., Bousset, L., Honoré, A., Rozas, N., et al. (2013). G51D $\alpha$-synuclein mutation causes a novel Parkinsonian-pyramidal syndrome. Ann. Neurol. 73, 459-471. doi: 10.1002/ana.23894

Li, J., Uversky, V. N., and Fink, A. L. (2001). Effect of familial Parkinson's disease point mutations $\mathrm{A} 30 \mathrm{P}$ and $\mathrm{A} 53 \mathrm{~T}$ on the structural properties, aggregation, and fibrillation of human $\alpha$-synuclein. Biochemistry 40, 11604-11613. doi: $10.1021 /$ bi010616g

Lin, M. T., and Beal, M. F. (2006). Mitochondrial dysfunction and oxidative stress in neurodegenerative diseases. Nature 443, 787-795. doi: 10.1038/nature05292

Liu, D., Jin, L., Wang, H., Zhao, H., Zhao, C., Duan, C., et al. (2008). Silencing $\alpha$-synuclein gene expression enhances tyrosine hydroxylase activity in MN9D cells. Neurochem. Res. 33, 1401-1409. doi: 10.1007/s11064-008-9599-7

Ljungberg, M. C., Ali, Y. O., Zhu, J., Wu, C. S., Oka, K., Zhai, R. G., et al. (2012). CREB-activity and NMNAT2 transcription are down-regulated prior to neurodegeneration, while NMNAT2 over-expression is neuroprotective, in a mouse model of human tauopathy. Hum. Mol. Genet. 21, 251-267. doi: $10.1093 / \mathrm{hmg} / \mathrm{ddr} 492$

Longhena, F., Faustini, G., Missale, C., Pizzi, M., Spano, P., and Bellucci, A. (2017). The contribution of $\alpha$-synuclein spreading to Parkinson's disease synaptopathy. Neural Plast. 2017:5012129. doi: 10.1155/2017/5012129

Lotharius, J., and Brundin, P. (2002a). Impaired dopamine storage resulting from $\alpha$-synuclein mutations may contribute to the pathogenesis of Parkinson's disease. Hum. Mol. Genet. 11, 2395-2407. doi: 10.1093/hmg/11.20.2395

Lotharius, J., and Brundin, P. (2002b). Pathogenesis of Parkinson's disease: dopamine, vesicles and alpha-synuclein. Nat. Rev. Neurosci. 3, 932-942. doi: $10.1038 / \mathrm{nrn} 983$

Lu, X., Kim-Han, J., Harmon, S., Sakiyama-Elbert, S. E., and O’Malley, K. L. (2014). The Parkinsonian mimetic, 6-OHDA, impairs axonal transport in dopaminergic axons. Mol. Neurodegener. 9:17. doi: 10.1186/1750-1326-9-17

Lundblad, M., Decressac, M., Mattsson, B., and Björklund, A. (2012). Impaired neurotransmission caused by overexpression of -synuclein in nigral dopamine neurons. Proc. Natl. Acad. Sci. U.S.A. 109, 3213-3219. doi: $10.1073 /$ pnas.1200575109

Mahlknecht, P., Seppi, K., and Poewe, W. (2015). The concept of prodromal Parkinson's disease. J. Parkinsons Dis. 5, 681-697. doi: 10.3233/JPD-150685

Maries, E., Dass, B., Collier, T. J., Kordower, J. H., and Steece-Collier, K. (2003). The role of alpha-synuclein in Parkinson's disease: insights from animal models. Nat. Rev. Neurosci. 4, 727-738. doi: 10.1038/nrn1199

Maroteaux, L., Campanelli, J. T., and Scheller, R. H. (1988). Synuclein: a neuronspecific protein localized to the nucleus and presynaptic nerve terminal. $J$. Neurosci. 8, 2804-2815.

Marques, O., and Outeiro, T. F. (2012). Alpha-synuclein: from secretion to dysfunction and death. Cell Death Dis. 3:e350. doi: 10.1038/cddis.2012.94

Martin, L. J., Pan, Y., Price, A. C., Sterling, W., Copeland, N. G., Jenkins, N. A., et al. (2006). Parkinson's disease alpha-synuclein transgenic mice develop neuronal mitochondrial degeneration and cell death. J. Neurosci. 26, 41-50. doi: 10.1523/JNEUROSCI.4308-05.2006

Marui, W., Iseki, E., Nakai, T., Miura, S., Kato, M., Uéda, K., et al. (2002). Progression and staging of Lewy pathology in brains from patients with dementia with Lewy bodies. J. Neurol. Sci. 195, 153-159. doi: 10.1016/S0022-510X(02)00006-0

Masliah, E., Rockenstein, E., Veinbergs, I., Mallory, M., Hashimoto, M., Takeda, A., et al. (2000). Dopaminergic loss and inclusion body formation in a-synuclein mice: implications for neurodegenerative disorders. Science 287, 1265-1269. doi: $10.1126 /$ science.287.5456.1265

Massano, J., and Bhatia, K. P. (2012). Clinical approach to Parkinson's disease: features, diagnosis, and principles of management. Cold Spring Harb. Perspect. Med. 2:a008870. doi: 10.1101/cshperspect.a008870 
Middleton, E. R., and Rhoades, E. (2010). Effects of curvature and composition on $\alpha$-synuclein binding to lipid vesicles. Biophysj 99, 2279-2288. doi: 10.1016/j.bpj.2010.07.056

Milnerwood, A. J., and Raymond, L. A. (2010). Early synaptic pathophysiology in neurodegeneration: insights from Huntington's disease. Trends Neurosci. 33, 513-523. doi: 10.1016/j.tins.2010.08.002

Mittelstaedt, T., Alvaréz-Baron, E., and Schoch, S. (2010). RIM proteins and their role in synapse function. Biol. Chem. 391, 599-606. doi: 10.1515/BC.2010.064

Mor, D. E., Tsika, E., Mazzulli, J. R., Gould, N. S., Kim, H., Daniels, M. J., et al. (2017). Dopamine induces soluble $\alpha$-synuclein oligomers and nigrostriatal degeneration. Nat. Neurosci. 20, 1560-1568. doi: 10.1038/nn.4641

Morales, I., Sanchez, A., Rodriguez-sabate, C., and Rodriguez, M. (2015). The degeneration of dopaminergic synapses in Parkinson's disease: a selective animal model. Behav. Brain Res. 289, 19-28. doi: 10.1016/j.bbr.2015.04.019

Mukherjee, K., Yang, X., Gerber, S. H., Kwon, H.-B., Ho, A., Castillo, P. E., et al. (2010). Piccolo and bassoon maintain synaptic vesicle clustering without directly participating in vesicle exocytosis. Proc. Natl. Acad. Sci. U.S.A. 107, 6504-6509. doi: 10.1073/pnas.1002307107

Murphy, D. D., Rueter, S. M., Trojanowski, J. Q., and Lee, V. M. (2000). Synucleins are developmentally expressed, and alpha-synuclein regulates the size of the presynaptic vesicular pool in primary hippocampal neurons. J. Neurosci. 20, 3214-3220.

Narhi, L., Wood, S. J., Steavenson, S., Jiang, Y., Wu, G. M., Anafi, D., et al. (1999). Both familial Parkinson's disease mutations accelerate alpha-synuclein aggregation. J. Biol. Chem. 274, 9843-9846. doi: 10.1074/jbc.274.14.9843

Nemani, V. M., Lu, W., Berge, V., Nakamura, K., Onoa, B., Lee, M. K., et al. (2010). Increased expression of $\alpha$-synuclein reduces neurotransmitter release by inhibiting synaptic vesicle reclustering after endocytosis. Neuron 65, 66-79. doi: 10.1016/j.neuron.2009.12.023

Nutt, J. G., Carter, J. H., and Sexton, G. J. (2004). The dopamine transporter: importance in Parkinson's disease. Ann. Neurol. 55, 766-773. doi: 10.1002/ana.20089

Ocampo, A., Liu, J., and Barrientos, A. (2013). $\mathrm{NAD}^{+}$salvage pathway proteins suppress proteotoxicity in yeast models of neurodegeneration by promoting the clearance of misfolded/oligomerized proteins. Hum. Mol. Genet. 22, 1699-1708. doi: 10.1093/hmg/ddt016

Oueslati, A., Ximerakis, M., and Vekrellis, K. (2014). Protein transmission, seeding and degradation: key steps for $\alpha$-synuclein prion-like propagation. Exp. Neurobiol. 23, 324-336. doi: 10.5607/en.2014.23.4.324

Pasanen, P., Myllykangas, L., Siitonen, M., Raunio, A., Kaakkola, S., Lyytinen, J., et al. (2014). A novel $\alpha$-synuclein mutation A53E associated with atypical multiple system atrophy and Parkinson's disease-type pathology. Neurobiol. Aging 35, 2180.e1-e5. doi: 10.1016/j.neurobiolaging.2014.03.024

Peng, X., Tehranian, R., Dietrich, P., Stefanis, L., and Perez, R. G. (2005). Alpha-synuclein activation of protein phosphatase $2 \mathrm{~A}$ reduces tyrosine hydroxylase phosphorylation in dopaminergic cells. J. Cell Sci. 118, 3523-3530. doi: $10.1242 /$ jcs.02481

Perez, R. G., Waymire, J. C., Lin, E., Liu, J. J., Guo, F., and Zigmond, M. J. (2002). A role for $\alpha$-synuclein in the regulation of dopamine biosynthesis. J. Neurosci. 22, 3090-3099.

Picconi, B., Piccoli, G., and Calabresi, P. (2012). Synaptic Dysfunction in Parkinson's Disease. Adv. Exp. Med. Biol. 970, 553-572. doi: 10.1007/978-3-7091-0932-8

Pickrell, A. M., and Youle, R. J. (2015). The roles of PINK1, Parkin, and mitochondrial fidelity in parkinson's disease. Neuron 85, 257-273. doi: 10.1016/j.neuron.2014.12.007

Pifl, C., Rajput, A., Reither, H., Blesa, J., Cavada, C., Obeso, J. A., et al. (2014). Is Parkinson's disease a vesicular dopamine storage disorder? Evidence from a study in isolated synaptic vesicles of human and nonhuman primate striatum. J. Neurosci. 34, 8210-8218. doi: 10.1523/JNEUROSCI.5456-13.2014

Pissadaki, E. K., and Bolam, J. P. (2013). The energy cost of action potential propagation in dopamine neurons: clues to susceptibility in Parkinson's disease. Front. Comput. Neurosci. 7:13. doi: 10.3389/fncom.2013.00013

Polymeropoulos, M. H. (1997). Mutation in the -Synuclein Gene Identified in Families with Parkinson's Disease. Science 276, 2045-2047. doi: 10.1126/science.276.5321.2045

Pranke, I. M., Morello, V., Bigay, J., Gibson, K., Verbavatz, J. M., Antonny, B., et al. (2011). $\alpha$-Synuclein and ALPS motifs are membrane curvature sensors whose contrasting chemistry mediates selective vesicle binding. J. Cell Biol. 194, 89-103. doi: $10.1083 /$ jcb.201011118

Quadrato, G., Nguyen, T., Macosko, E. Z., Sherwood, J. L., Yang, S. M., Berger, D. R., et al. (2017). Cell diversity and network dynamics in photosensitive human brain organoids. Nature 545, 48-53. doi: 10.1038/nature22047

Rallis, A., Lu, B., and Ng, J. (2013). Molecular chaperones protect against JNK- and Nmnat-regulated axon degeneration in Drosophila. J. Cell Sci. 126, 838-849. doi: $10.1242 /$ jcs. 117259

Riemensperger, T., Issa, A., Pech, U., Coulom, H., Nguyễn, M.-V., Cassar, M., et al. (2013). A single dopamine pathway underlies progressive locomotor deficits in a Drosophila model of Parkinson disease. Cell Rep. 5, 952-960. doi: 10.1016/j.celrep.2013.10.032

Rodriguez, J. A., Ivanova, M. I., Sawaya, M. R., Cascio, D., Reyes, F. E., Shi, D., et al. (2015). Structure of the toxic core of $\alpha$-synuclein from invisible crystals. Nature 525, 486-490. doi: 10.1038/nature 15368

Roy, S. (2017). Synuclein and dopamine: the Bonnie and Clyde of Parkinson's disease. Nat. Neurosci. 20, 1514-1515. doi: 10.1038/nn.4660

Saheki, Y., and De Camilli, P. (2012). Synaptic vesicle endocytosis. Cold Spring Harb. Perspect. Biol. 4:a005645. doi: 10.1101/cshperspect.a005645

Satake, W., Nakabayashi, Y., Mizuta, I., Hirota, Y., Ito, C., Kubo, M., et al. (2009). Genome-wide association study identifies common variants at four loci as genetic risk factors for Parkinson's disease. Nat. Genet. 41, 1303-1307. doi: $10.1038 /$ ng. 485

Schirinzi, T., Madeo, G., Martella, G., Maltese, M., Picconi, B., Calabresi, P., et al. (2016). Early synaptic dysfunction in Parkinson's disease: insights from animal models. Mov. Disord. 31, 802-813. doi: 10.1002/mds. 26620

Schoch, S., and Gundelfinger, E. D. (2006). Molecular organization of the presynaptic active zone. Cell Tiss. Res. 326, 379-391. doi: 10.1007/s00441-006-0244-y

Schulz-Schaeffer, W. J. (2010). The synaptic pathology of $\alpha$-synuclein aggregation in dementia with Lewy bodies, Parkinson's disease and Parkinson's disease dementia. Acta Neuropathol. 120, 131-143. doi: 10.1007/s00401-010-0711-0

Schulz-Schaeffer, W. J. (2015). Is cell death primary or secondary in the pathophysiology of idiopathic Parkinson's disease? Biomolecules 5, 1467-1479. doi: 10.3390/biom 5031467

Scott, D. A., Tabarean, I., Tang, Y., Cartier, A., Masliah, E., and Roy, S. (2010). A pathologic cascade leading to synaptic dysfunction in alpha-synuclein-induced neurodegeneration. J. Neurosci. 30, 8083-8095. doi: 10.1523/JNEUROSCI.1091-10.2010

Scott, D., and Roy, S. (2012). $\alpha$-Synuclein inhibits intersynaptic vesicle mobility and maintains recycling-pool homeostasis. J. Neurosci. 32, 10129-10135. doi: 10.1523/JNEUROSCI.0535-12.2012

Seeman, P., and Niznik, H. B. (1990). Dopamine disease in Parkinson's and schizophrenia. FASEB J. 4, 2737-2744.

Sharma, M., Burré, J., and Südhof, T. C. (2011). CSP $\alpha$ promotes SNARE-complex assembly by chaperoning SNAP-25 during synaptic activity. Nat. Cell Biol. 13, 30-39. doi: 10.1038/ncb2131

Shirataki, H., Kaibuchi, K., Sakoda, T., Kishida, S., Yamaguchi, T., Wada, K., et al. (1993). Rabphilin-3A, a putative target protein for smg p25A/rab3A p25 small GTP-binding protein related to synaptotagmin. Mol. Cell. Biol. 13, 2061-2068. doi: 10.1128/MCB.13.4.2061

Simón-Sánchez, J., Schulte, C., Bras, J. M., Sharma, M., Raphael Gibbs, J., Berg, D., et al. (2009). Genome-wide association study reveals genetic risk underlying Parkinson's disease. Nat. Genet. 41, 1308-1312. doi: 10.1038/ng.487

Singleton, A. B. (2003). Alpha-synuclein locus triplication causes Parkinson's disease. Science 302, 841-841. doi: 10.1126/science.1090278

Spillantini, M. G., Schmidt, M. L., Lee, V. M.-Y., Trojanowski, J. Q., Jakes, R., and Goedert, M. (1997). alpha-Synuclein in lewy bodies. Nature 388, 839-840. doi: $10.1038 / 42166$

Stefanis, L. (2012). Alpha-synuclein in Parkinson's disease. Cold Spring Harb. Perspect. Med. 2:a009399. doi: 10.1101/cshperspect.a009399

Stenmark, H., Parton, R. G., Steele-Mortimer, O., Lütcke, A., Gruenberg, J., and Zerial, M. (1994). Inhibition of rab5 GTPase activity stimulates membrane fusion in endocytosis. EMBO J. 13, 1287-96.

Südhof, T. C. (2000). The synaptic vesicle cycle revisited. Neuron 28, 317-320. doi: 10.1016/S0896-6273(00)00109-4

Südhof, T. C. (2004). The synaptic vesicle cycle. Annu. Rev. Neurosci. 27, 509-547. doi: 10.1146/annurev.neuro.26.041002.131412 
Südhof, T. C. (2012). The presynaptic active zone. Neuron 75, 11-25. doi: 10.1016/j.neuron.2012.06.012

Südhof, T. C. (2013a). A molecular machine for neurotransmitter release: synaptotagmin and beyond. Nat. Med. 19, 1227-1231. doi: 10.1038/nm.3338

Südhof, T. C. (2013b). Neurotransmitter release: The last millisecond in the life of a synaptic vesicle. Neuron 80, 675-690. doi: 10.1016/j.neuron.2013.10.022

Südhof, T. C., and Rizo, J. (2011). Synaptic vesicle exocytosis. Cold Spring Harb. Perspect. Biol. 3:pii: a005637. doi: 10.1101/cshperspect.a005637

Sung, J. Y., Kim, J., Paik, S. R., Park, J. H., Ahn, Y. S., and Chung, K. C. (2001). Induction of neuronal cell death by Rab5A-dependent Endocytosis of AlphaSynuclein. J. Biol. Chem. 276, 27441-27448. doi: 10.1074/jbc.M101318200

Tagliaferro, P., and Burke, R. E. (2016). Retrograde axonal degeneration in Parkinson disease. J. Parkinsons. Dis. 6, 1-15. doi: 10.3233/JPD-150769

Takamori, S., Holt, M., Stenius, K., Lemke, E. A., Grønborg, M., Riedel, D., et al. (2006). Molecular anatomy of a trafficking organelle. Cell 127, 831-846. doi: 10.1016/j.cell.2006.10.030

Tehranian, R., Montoya, S. E., Van Laar, A. D., Hastings, T. G., and Perez, R. G. (2006). Alpha-synuclein inhibits aromatic amino acid decarboxylase activity in dopaminergic cells. J. Neurochem. 99, 1188-1196. doi: 10.1111/j.1471-4159.2006.04146.x

Tosatto, L., Horrocks, M. H., Dear, A. J., Knowles, T. P. J., Dalla Serra, M., Cremades, N., et al. (2015). Single-molecule FRET studies on alpha-synuclein oligomerization of Parkinson's disease genetically related mutants. Sci. Rep. 5:16696. doi: $10.1038 /$ srep16696

Vargas, K. J., Makani, S., Davis, T., Westphal, C. H., Castillo, P. E., and Chandra, S. S. (2014). Synucleins regulate the kinetics of synaptic vesicle endocytosis. J. Neurosci. 34, 9364-9376. doi: 10.1523/JNEUROSCI.4787-13.2014

Vargas, K. J., Schrod, N., Davis, T., Fernandez-Busnadiego, R., Taguchi, Y. V., Laugks, U., et al. (2017). Synucleins have multiple effects on presynaptic architecture. Cell Rep. 18, 161-173. doi: 10.1016/j.celrep.2016.12.023

Vaughan, R. A., and Foster, J. D. (2013). Mechanisms of dopamine transporter regulation in normal and disease states. Trends Pharmacol. Sci. 34, 489-496. doi: 10.1016/j.tips.2013.07.005

Venda, L. L., Cragg, S. J., Buchman, V. L., and Wade-Martins, R. (2010). Alphasynuclein and dopamine at the crossroads of Parkinson's disease. Trends Neurosci. 33, 559-568. doi: 10.1016/j.tins.2010.09.004

Volpicelli-Daley, L. A., Luk, K. C., Patel, T. P., Tanik, S. A., Riddle, D. M., Stieber, A., et al. (2011). Exogenous $\alpha$-synuclein fibrils induce lewy body pathology leading to synaptic dysfunction and neuron death. Neuron 72, 57-71. doi: 10.1016/j.neuron.2011.08.033

Wang, S. S. H., Held, R. G., Wong, M. Y., Liu, C., Karakhanyan, A., and Kaeser, P. S. (2016). Fusion competent synaptic vesicles persist upon active zone disruption and loss of vesicle docking. Neuron 91, 777-791. doi: 10.1016/j.neuron.2016.07.005

Wang, Y. C., Lauwers, E., and Verstreken, P. (2017). Presynaptic protein homeostasis and neuronal function. Curr. Opin. Genet. Dev. 44, 38-46. doi: 10.1016/j.gde.2017.01.015

Wang, Y., Okamoto, M., Schmitz, F., Hofmann, K., and Südhof, T. C. (1997). Rim is a putative Rab3 effector in regulating synaptic-vesicle fusion. Nature 388, 593-598. doi: $10.1038 / 41580$
Wersinger, C., and Sidhu, A. (2003). Attenuation of dopamine transporter activity by alpha-synuclein. Neurosci. Lett. 340, 189-192. doi: 10.1016/S0304-3940(03)00097-1

Wersinger, C., Prou, D., Vernier, P., Niznik, H. B., and Sidhu, A. (2003). Mutations in the lipid-binding domain of alpha-synuclein confer overlapping, yet distinct, functional properties in the regulation of dopamine transporter activity. Mol. Cell. Neurosci. 24, 91-105. doi: 10.1016/S1044-7431(03) 00124-6

Xu, J., Kao, S.-Y., Lee, F. J. S., Song, W., Jin, L.-W., and Yankner, B. A. (2002). Dopamine-dependent neurotoxicity of alpha-synuclein: a mechanism for selective neurodegeneration in Parkinson disease. Nat. Med. 8, 600-606. doi: 10.1038/nm0602-600

Xu, J., Wu, X.-S., Sheng, J., Zhang, Z., Yue, H.-Y., Sun, L., et al. (2016). Alphasynuclein mutation inhibits endocytosis at mammalian central nerve terminals. J. Neurosci. 36, 4408-4414. doi: 10.1523/JNEUROSCI.3627-15.2016

Yamamoto, S., Fukae, J., Mori, H., Mizuno, Y., and Hattori, N. (2006) Positive immunoreactivity for vesicular monoamine transporter 2 in Lewy bodies and Lewy neurites in substantia nigra. Neurosci. Lett. 396, 187-191. doi: 10.1016/j.neulet.2005.11.068

Zang, S., Ali, Y. O., Ruan, K., and Zhai, R. G. (2013). Nicotinamide mononucleotide adenylyltransferase maintains active zone structure by stabilizing Bruchpilot. EMBO Rep. 14, 87-94. doi: 10.1038/embor.2012.181

Zarranz, J. J., Alegre, J., Gómez-Esteban, J. C., Lezcano, E., Ros, R., Ampuero, I., et al. (2004). The new mutation, E46K, of $\alpha$-Synuclein Causes Parkinson and Lewy Body Dementia. Ann. Neurol. 55, 164-173. doi: 10.1002/ana.10795

Zhai, R. G., Cao, Y., Hiesinger, P. R., Zhou, Y., Mehta, S. Q., Schulze, K. L., et al. (2006). Drosophila NMNAT maintains neural integrity independent of its NAD synthesis activity. PLoS Biol. 4, 2336-2348. doi: 10.1371/journal.pbio.0040416

Zhai, R. G., Zhang, F., Hiesinger, P. R., Cao, Y., Haueter, C. M., and Bellen, H. J. (2008). NAD synthase NMNAT acts as a chaperone to protect against neurodegeneration. Nature 452, 887-891. doi: 10.1038/nature06721

Zhang, L., Zhang, C., Zhu, Y., Cai, Q., Chan, P., Uéda, K., et al. (2008). Semi-quantitative analysis of $\alpha$-synuclein in subcellular pools of rat brain neurons: an immunogold electron microscopic study using a C-terminal specific monoclonal antibody. Brain Res. 1244, 40-52. doi: 10.1016/j.brainres.2008.08.067

Conflict of Interest Statement: The authors declare that the research was conducted in the absence of any commercial or financial relationships that could be construed as a potential conflict of interest.

The handling Editor declared a shared affiliation, though no other collaboration, with the authors.

Copyright (c) 2018 Bridi and Hirth. This is an open-access article distributed under the terms of the Creative Commons Attribution License (CC BY). The use, distribution or reproduction in other forums is permitted, provided the original author(s) and the copyright owner are credited and that the original publication in this journal is cited, in accordance with accepted academic practice. No use, distribution or reproduction is permitted which does not comply with these terms. 